This dissertation has been $\quad 62-3017$ microfilmed exactly as received

MARCHETTI, Marco Anthony, 1936-

REACTION OF QUERCUS MACROCARPA TO

INFECTION BY CERATOCYSTIS FAGACEARUM.

Iowa State University of Science and Technology

Ph.D., 1962

Botany

University Microfilms, Inc., Ann Arbor, Michigan 


\title{
REACTION OF QUERCUS MACROCARPA TO INFECTION BY CERATOCYSTIS FAGACEARUM by
} Marco Anthony Marchetti

\author{
A Dissertation Submitted to the \\ Graduate Faculty in Partial Fulfillment of \\ The Requirements for the Degree of \\ DOCTOR OF PHILOSOPHY
} Major Subject: Plant Pathology

Approved:

Signature was redacted for privacy.

In Charge of Major W6rk

Signature was redacted for privacy.

Head 'of Major Depattment

Signature was redacted for privacy.

Deấ of Gradkate College

Iowa State University

of Science and Technology

Ames, Iowa

1962 
TABLE OF CONTENTS

Page

I. INTRODUCTION

II. LITERATURE REVIEW 3

A. Host-parasite Interactions in the oak wilt Disease

B. Competition in vivo among Isolates of $\underline{C}$. fagacearum

III. MATERIALS AND METHODS

A. Selection of Host Material 13

B. Inoculum 13

C. Field Procedures 14

1. Inoculations - 1960 series 14

2. Sampling - 1960 series 15

3. Modifications of procedures - 1961 series 21

D. Isolation Technique " 26

$\begin{array}{ll}\text { E. Microtechnique } & 27\end{array}$

IV. RESULTS 30

A. Frequency and Distribution of oak wilt among
Inoculated Branches

B. Internal Reactions to Infection by C. fagacearum 40

C. Healing of Drill Wounds 64

D. Other Wound Phenomena 77

$\begin{array}{ll}\text { V. DISCUSSION } & 95\end{array}$

$\begin{array}{ll}\text { VI. SUMMARY } & 107\end{array}$

VII. IITERATURE CITED 110

VIII. ACKNOWLEDGEMENTS $\quad 114$ 
I. INTRODUCTION

Oak wilt, a vascular disease caused by Ceratocystis fagacearum (Bretz) Hunt, results in death, usually within a growing season, for members of the red oak group. However, members of the white oak group may survive for several years after initial infection, and frequently appear to recover from the disease. While searching for reasons why white oaks may survive temporarily or apparently recover from oak wilt, it was observed that tangential spread of $\underline{C}$. fagacearum and subsequent occlusion of vessels often was limited, thereby leaving sectors of healthy, functional conductive tissue. often a new ring of sapwood, which usually was not invaded by C. fagacearum, was produced the following spring. In contrast, almost all functional vessels of diseased red oaks were found to be occluded with tyloses, and the diseased trees usually. died within the growing season. If diseased red oaks survived into the following growing season, invasion by the pathogen into newly-formed sapwood occurred rapidly, followed by death of the tree.

Recently another phenomenon which may be instrumental in the resistance of white oaks to oak wilt was discovered. Bands of wilt-induced, disease-free tissue containing numerous small vessels were produced radially adjacent to diseased xylem of white oaks (Quercus alba $L_{\text {.) }}$ during the same growing season in which infection occurred. The following spring an 
apparently normal increment of sapwood was produced. The major purposes of this investigation were to determine the existence of the aforementioned phenomenon in diseased bur oaks (‥ macrocarpa.Michx.), its frequency, and conditions affecting its development. Attention was given to cambial activity during the growing season and its possible influence on the initiation of wilt-induced xylem. The reactions of bur oak to other pathological conditions were observed in the hope of obtaining a better general understanding of such reactions.

Amyloplasts are among the most abundant inclusions of uninjured xylary and medullary parenchyma and frequently of living tyloses of bur oak branches, indicating starch is an important form of food reserve. Observations were made of fluctuations in starch accumulation during the growing season and the effects of oak wilt and other pathological conditions on the accumulation of starch.

Cultural studies of naturally and artificially infected oaks have indicated that competition among isolates of $\underline{c}$. fagacearum exists in vivo. In order to investigate further this phenomenon, two macroscopically distinct isolates of c. fagacearum were used as inocula. 
II. LITERATURE REVIEW

A. Host-parasite Interactions in the oak Wilt Disease

Oak wilt is a disease of the vascular tissue of oaks incited by the fungus, Ceratocystis fagacearum. All species of oak chat have been tested, both indigenous and exotic, are susceptible to the disease. As a result of fungal activity in an infected tree, the movement of solutions through conductive tissue is gradually stopped, apparently by means of vascular occlusions such as tyloses and gum deposits. Consequently the foliage wilts from loss of water by evaporation. The disease is almost always fatal to individuals of the red oak group. Recovery of white oaks from the disease has been observed on numerous occasions since 1941.

The oak wilt organism must be introduced directly into the xylem of susceptible trees (Henry and Riker 1947). Fresh wounds, less than two days old, provide the most favorable penetration courts (Zuckerman 1954). In Wisconsin, root-graft transmission of the pathogen from diseased to healty members of the red oak group was considered important in the local spread of the disease (Kuntz and Riker 1950). Studies in the Appalachian region and in southern Missouri indicated rootgraft transmission was of little importance (Boyce 1957, Jones and Partridge 1961; Staley and True 1952). Overland transmission of the organism appears to be effected by insect 
vectors, notably members of the family Nitidulidae (Dorsey and Leach 1956).

Before and during incipient stages of foliar wilt, only sparse amounts of mycelium have been observed in the vessels of diseased trees (Fergus and Wharton 1957a; Struckmeyer et al. 1958; Young 1949). C. fagacearum has been isolated frequently from wood adjacent to sections used for microscopic observations (Fergus and Wharton 1957a). The fungus occasionally has been isolated from all parts of red oaks as much as a week before the first foliar symptoms appeared (Kuntz et al. 1952; Marchetti 1959). In other instances, the oak wilt organism was recovered only from scattered locations in red oaks in more advanced stages of wilt (Marchetti 1959). From the above observations it has been concluded that conidia were transported in the transpiration stream to various parts of the infected trees where new centers of infection were established.

It was reported that "cambial growth" ceased in northern pin oaks (‥ ellipsoidalis Hill) within a few days after foliar symptoms were first observed (Kozlowski et al. 1961). During more advanced stages of wilt and defoliation, extensive mycelium develops in the vessels and penetrates through pits into the adjacent ray and xylary parenchyma, progressing radially through the rays to the cambium and the inner bark. If conditions are favorable, the unique mat-and- 
pad structures develop between the wood and bark, ultimately forcing the bark to split and exposing the mat to infestation by insects. (Struckmeyer and Kuntz 1954)

In a more recent investigation, black jack oaks

(Q. marilandica Muenchh.) were inoculated with cultures grown on a medium containing sulfur ${ }^{35}$. Utilizing radioautographic techniques, hyphae were observed in the ray and xylary parenchyma before symptoms appeared. Hyphae passed considerable distances through the middle lamella. Occasionally, small vessels were observed to be filled with hyphae and spores considerably smaller than are considered usual for C. fagacearum. (Wilson 1961)

The scarcity of mycelium in the vessels was noted before and during incipient wilt. However, conidiophores originating in the parenchyma adjacent to vessels and protruding through pits into the vessel lumina were observed. (Wilson 1961) The nature of the wilting mechanism of $\underline{c}$. fagacearum is largely unknown (True et al. 1960). Certainly the severe reduction of water movement is a major factor in the wilting process. Infected vessels become occluded with tyloses and gum deposits several days before the initial foliar wilt symptoms are visible (Beckman et al. 1953; Fergus and Wharton 1957a; Parmeter and Kuntz 1954; Struckmeyer et al. 1954). Probably on the basis of earlier works dealing with tyloses (Chattaway 1949; Klein 1923), the question has arisen whether 
tylosis formation is the cause or result of cessation of vascular conduction. They have been found to arise in many genera from other causes such as drought, wounding and senescence (Chattaway 1949; Gerry 1914). By artificial defoliation of northern pin oaks and use of Rubidium 86 carbonate injections, decline in water movement without tylosis formation was demonstrated. In those trees that were inoculated

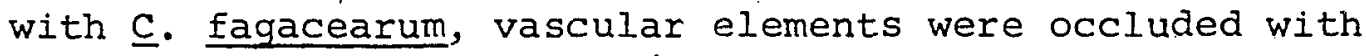
tyloses about three weeks after inoculation, regardless of the time of defoliation (Beckman et al. 1953). These results indicate tylosis formation is a response of the host to action of the pathogen and that tyloses cause rather than result from the decline in water movement in the vessels. The existence of growth stimulants in culture filtrates of $\underline{c}$. fagacearum has been demonstrated (Fergus and wharton 1957b). It has been suggested that invasion of the ray parenchyma by the pathogen stimulates tylosis formation (Wilson 1961).

The tendency of species of the white oak group to live longer than those of the red oak group, both naturally and when afflicted with oak wilt, has been observed for a long time (Henry et al. 1944). Since the frequency of intraspecific as well as interspecific root grafts is very low in the white oak group, white oaks are less susceptible to basal infections, which generally result in more widespread initial symptoms and more rapid death in red oaks (Kuntz et al. 1952). 
An intensive study of the development of oak wilt in bur oak was conducted in Wisconsin (Parmeter et al. 1956). Symptomatic tyloses and vascular discolorations usually were confined to narrow vertical bands of xylem in the main stem and branches vascularly connected with diseased sectors of the main stem. These branches exhibited foliar wilt during the growing season. Often a new layer of sapwood was laid down over the infected, plugged sectors during the following growing season and symptoms appeared sporadically during the sumer. Sometimes no foliar symptoms appeared. Trees having oak wilt, but showing no foliar symptoms for one or two years subsequent to the initial infection, only infrequently yielded the oak wilt fungus in culture; nor did these trees develop symptomatic tyloses or vascular discoloration in increments produced subsequent to the infected ring.

Other bur oaks showed recurrent symptoms for several years following the initial infection. These trees yielded c. fagacearum in culture, and had developed tyloses and vascular discoloration in increments produced in years when foliar symptoms appeared. It was noted in 20 of 25 trees with recurring symptoms that galleries of the two-lined chestnut borer (Agrilus bilineatus web.) penetrated through the new wood into the previous year's diseased tissue, thereby affording easy entry by the pathogen into the current growth. No galleries were observed in recovered bur oaks. (Parmeter 
et al. 1956)

In a study conducted with naturally infected white oaks, 10 of the 21 wilting branches sampled did not yield $\underline{C}$. fagacearum in culture (Boyce 1961). The investigator concluded that the oak wilt organism was not uniformly distributed in some of the trees.

In Missouri, mortality of white oaks from oak wilt has been found to be lower than previously had been expected. Over half of the infected white oaks studied developed no new symptoms of oak wilt over a period of several years after infection had occurred. Only a small percentage had died over the period of observation. Concern has been expressed that "recovered" trees may serve as reservoirs of inoculum. (Jones 1958)

In 1959 a new phenomenon was reported in white oaks both artificially and naturally infected by $\underline{c}$. fagacearum. Several young white oaks (Q. $\underline{\text { alba) }}$ were inoculated in early May with C. Eagacearum, and scattered foliar symptoms appeared a month later. The trees remained alive for the duration of the growing season. Microscopic investigations of branch sections revealed the formation of sectors of xylem containing numerous, somewhat smaller vessels adjacent to diseased sectors of early wood vessels. In cross section the two bands of vessels were separated by a sharply defined line of "very small cells". The second band was produced during the same growing season in 
which infection occurred, and apparently it remained free of disease. (Schoeneweiss 1959)

The same phenomenon was observed in white oaks naturally infected several years before they were sampled. Judging from the photomicrograph presented in the paper, these trees (at least the one photographed) had become infected early in the growing season. In years following the initial infection, xylem differentiation returned to the normal ring-porous pattern. (Schoeneweiss 1959)

A similar response to oak wilt by a pin oak (․ palustris Muenchh.) occurred when Vancide 51 was applied as a bole injection in early August 1956, two days before the tree was inoculated with $\subseteq$. fagacearum. Initial foliar symptoms appeared 43 days after inoculation. In 1957 the pin oak displayed scattered symptoms and considerable suckering. Microscopic examination revealed the vessels produced in 1956 were occluded, but the entire increment laid down in 1957 appeared almost identical to the band of open vessels observed in white oaks. Many more vessels were occluded in the 1957 band of the pin oak than in the wilt-induced band of open vessels in white oak, indicating the band in the pin oak was not entirely disease-free. (Schoeneweiss 1959)

No double-banding was observed in sectors with woundinduced tyloses, which indicated to the investigator that the oak wilt pathogen was involved in some way with the mechanism 
effecting this newly-discovered response (Schoeneweiss 1959).

In 1940 , a somewhat similar response to severe wounding was noted in young branches of oak. The xylem showed signs of reversion to the diffuse-porous arrangement of vessels, especially in the sector formed directly from the injured, portion and "in the wound cap proper". Latewood vessels were larger in diameter than usual and earlywood vessels formed after wounding were reduced in diameter. (Gilbert. 1940)

In one of the photomicrographs (Schoeneweiss 1959, p. 337) the earlywood vessels formed in the year following initial infection appear noticeably smaller than those produced previously or subsequently.

B. Competition in vivo among Isolates of $\underline{C}$. fagacearum

Insects, especially nitidulids, have been implicated as vectors in the overland transmission of oak wilt (Dorsey et al. 1953; Jewell 1956; Norris 1953) as well as spermatizing agents because of their movements among fruiting structures of C. Eagacearum and fresh wounds on oaks (Craighead et al. 1953; Leach et al. 1952). Nitidulids have been found to breed and deposit eggs on the mats, and within a few days the mats may become heavily infested with larvae (Dorsey and Leach 1956). Because of the constant association of certain insects with the fruiting structures of $\underline{c}$. fagacearum, the feeding habits 
of these insects, and the stickiness of the ascospore matrix, it is felt that ascospores are important as inoculum for over-, land spread of oak wilt (Craighead et al. 1953). The relative frequencies of the two compatability types found in certain areas lend support to the above (Barnett and Staley 1953; Yount 1954).

Assuming that ascospores are important as inoculum in overland spread of oak wilt, many trees are inoculated with spores of both compatability types. However, only rarely have both compatability types of $\underline{c}$. fagacearum been isolated from the same naturally infected trees (Barnett and Staley 1953; Boyce and Garren 1953; Hepting et al. 1951).

Investigations were conducted by using mixed culture inoculations in which red oaks were inoculated with various mixtures of conidia or ascospores of different mating types ( $A$ and $B$ ) and color types (gray and albino) (Barnett and Jewell 1954). Upon reisolation, usually only one matingcolor type was yielded from any one tree, although there seemed to be no significant predominance of one mating-color type over others: It was found that two different isolates could become established more readily within a single tree if they were introduced at different loci on the main stem. In several instances both isolates were recovered as a mixture in isolations from the bole. However, in no instance were both isolates recovered from a single branch (Marchetti 1960). 
The reasons for the unexpected survival of only one type and its spread throughout most infected trees are not known. It seems likely to result from competition among thalli for survival within the tree, and apparently survival of one isolate over others is determined during or shortly after germination of spores in the penetration court (Barnett and Jewell 1954). 


\section{MATERIALS AND METHODS}

\section{A. Selection of Host Material}

A week before the first series of inoculations in 1960, 40 bur oaks were selected in Pilot knob State Park, Hancock County, Iowa, and the number of usable branches on each was estimated from the ground. Those trees used in 1961 were not selected in advance of inoculation date. The selected trees usually were in the suppressed or intermediate crown class, since larger trees had too few branches of desired size within reach. Branches used in this study varied in d.o.b. (diameter outside bark) from 9 to $21 \mathrm{~mm}$ and in length from 45 to $180 \mathrm{~cm}$.

The trees were located on a map of the park, and numbered on the bole with yellow paint.

\section{B. Inoculum}

Two isolates of $C$. fagacearum were used as inoculum. Isolate 2126B, an albino mutant, originally had been obtained from Dr. T. W. Bretz, University of Missouri. The parent culture used in these studies had been reisolated from an artificially infected northern pin oak at Pilot Knob state Park. Isolate 50B, exhibiting typical gray-brown coloration in culture, was isolated from a naturaliy infected northern pin oak at Pilot Knob Park. on 19 May 1960, one slant of each 
isolate was subcultured by mass transfers to 12 slants each of 2 percent PDA. The subcultures were incubated for three weeks at $22-24^{\circ} \mathrm{C}$. One slant of each isolate was used as a source of inoculum for each series of inoculations. After the incubation period, subcultures were stored at $5^{\circ} \mathrm{C}$ until needed. Those not used were kept over the winter at $5^{\circ} \mathrm{C}$. Using the same procedures as described above, one, subculture of each isolate was used as the parent culture for subcultures used in the 1961 series of inoculations.

The conidial suspensions were made on the night before inoculations. The suspensions used for the 1960 inoculations contained approximately $10^{5}$ spores per $\mathrm{ml}$; for the 1961 inoculations, suspensions contained approximately $2 \times 10^{5}$ spores per $\mathrm{ml}$.

\section{Field Procedures}

1. Inoculations - 1960 series

Beginning on 9 June 1960, six series of inoculations were made at two-week intervals. In each series, 48 branches were inoculated with the two isolates of $\underline{C}$. fagacearum, and six branches were injected with sterile distilled water. Seven samples of six inoculated branches each were collected at weekly intervals. Eight weeks after inoculation three waterinjected checks were collected to determine the effects of 
wounding alone (Table 1). Six inoculated.branches and three checks of each series were left for collection in 1961.

Inoculations were made at diametrically opposed loci on sides of branches, one isolate being introduced at each locus. Two small holes were drilled into the xylem at the base of each branch, with a finger-twist brace and 0.0250 inch bit. one or two drops of the appropriate spore suspension were injected into each hole with disposable-type syringes and needles. The drops of suspension were not readily drawn into the xylem. A separate syringe was used for each isolate throughout a series. The locus at which the white isolate was introduced was marked with a red wax pencil.

Checks were drilled as described above. Sterile distilled water was injected into one hole, and the other hole was left untreated. The water-injected hole was marked with a red wax pencil.

As each branch was treated, its aspect was noted, an estimate of its exposure to the sun was made, and the branch was tagged for future identification. Checks were selected on trees having other branches inoculated with the oak wilt pathogen. Consideration was given to vertical alignment with and proximity to inoculated branches in selecting branches for checks.

2. Sampling - 1960 series

Branches were sampled at random within each series. The branches were sawed'flush with the main stem. Branch length 
Table 1. Inoculation and sampling schedule for 1960 series of experiments on bur oaks in Pilot Knob State Park, Hancock County, Iowa

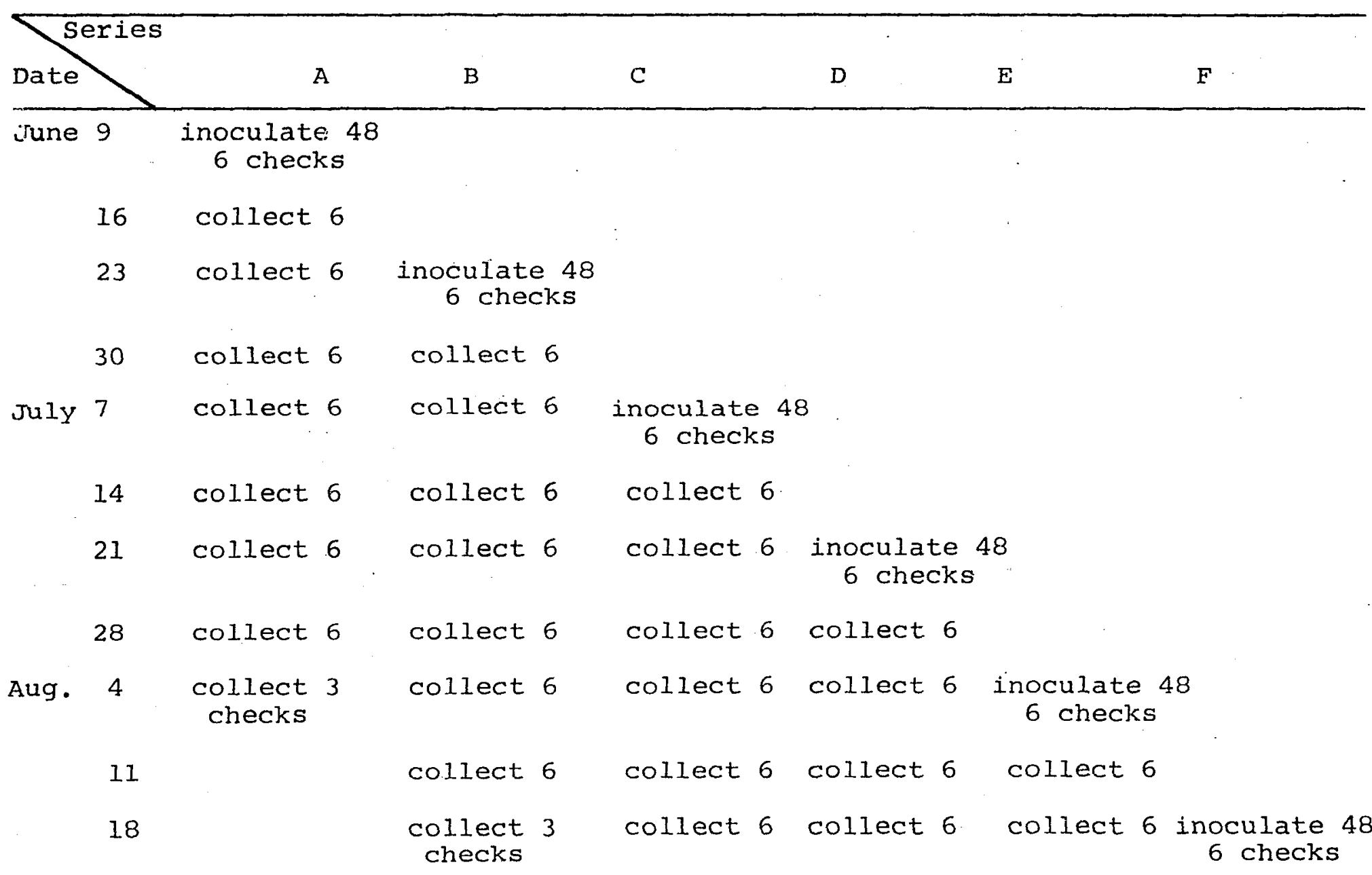


Table 1. (Continued)

\begin{tabular}{|c|c|c|c|c|c|c|c|c|}
\hline & & $\mathrm{A}$ & B & C & D & & $E$ & $F$ \\
\hline Aug. & 25 & & & collect 6 & collect & 6 & collect 6 & collect 6 \\
\hline Sept. & - 1 & & & $\begin{array}{c}\text { collect } 3 \\
\text { checks }\end{array}$ & collect & 6 & collect 6 & collect 6 \\
\hline & 8 & & & & collect & 6 & collect 6 & collect 6 \\
\hline & 15 & & & & $\begin{array}{c}\text { collect } \\
\text { checks }\end{array}$ & 3 & collect 6 & collect 6 \\
\hline & 22 & & & & & & collect 6 & collect 6 \\
\hline & 29 & & & & & & $\begin{array}{c}\text { collect } 3 \\
\text { checks }\end{array}$ & collect 6 \\
\hline oct. & 6 & & & & & & & collect 6 \\
\hline & 13 & & & & & & & $\begin{array}{c}\text { collect } 3 \\
\text { checks }\end{array}$ \\
\hline
\end{tabular}


and number of leaves were recorded. A linear reference line was inscribed on the bark of those portions of the branch that were to be sampled. The reference line was on the same radius as the inoculation site of the albino isolate. A Iine sketch of each branch was made. Portions of the branch to be sampled and any wilting parts or other abnormality that might become evident in microtomed material were marked on the sketch.

All samples to be used for sectioning were cut with a coping saw and trimmed with a razor blade. Starting immediately above the drill holes, adjacent samples were removed for longitudinal sectioning, transverse sectioning, and culturing, respectively. Often samples including the inoculation sites were taken for transverse or longitudinal sectioning (Figure 1). Samples for longitudinal sectioning were eight $\mathrm{mm}$ iong, and those for cross sectioning were $12 \mathrm{~mm}$ long. Samples for culturing were $10-15 \mathrm{~cm}$ in length. Samples for sectioning on the microtome were notched at the basal end in the radius of the reference line and immersed, with an appropriate label, in bottles of FAA. Age, a.o.b. and d.i.b. (diameter inside bark) were determined from the basal surface of the lowermost sample.

Depending upon the length and deliquescence of a branch, one to four additional samples were taken for culturing, and one or two additional samples were taken for sectioning, using 
Figure 1. Sampling of bur oak branches and the ultimate disposition of each sample; except for samples including inoculation wounds, other parts of the branches were sampled in the same manner 

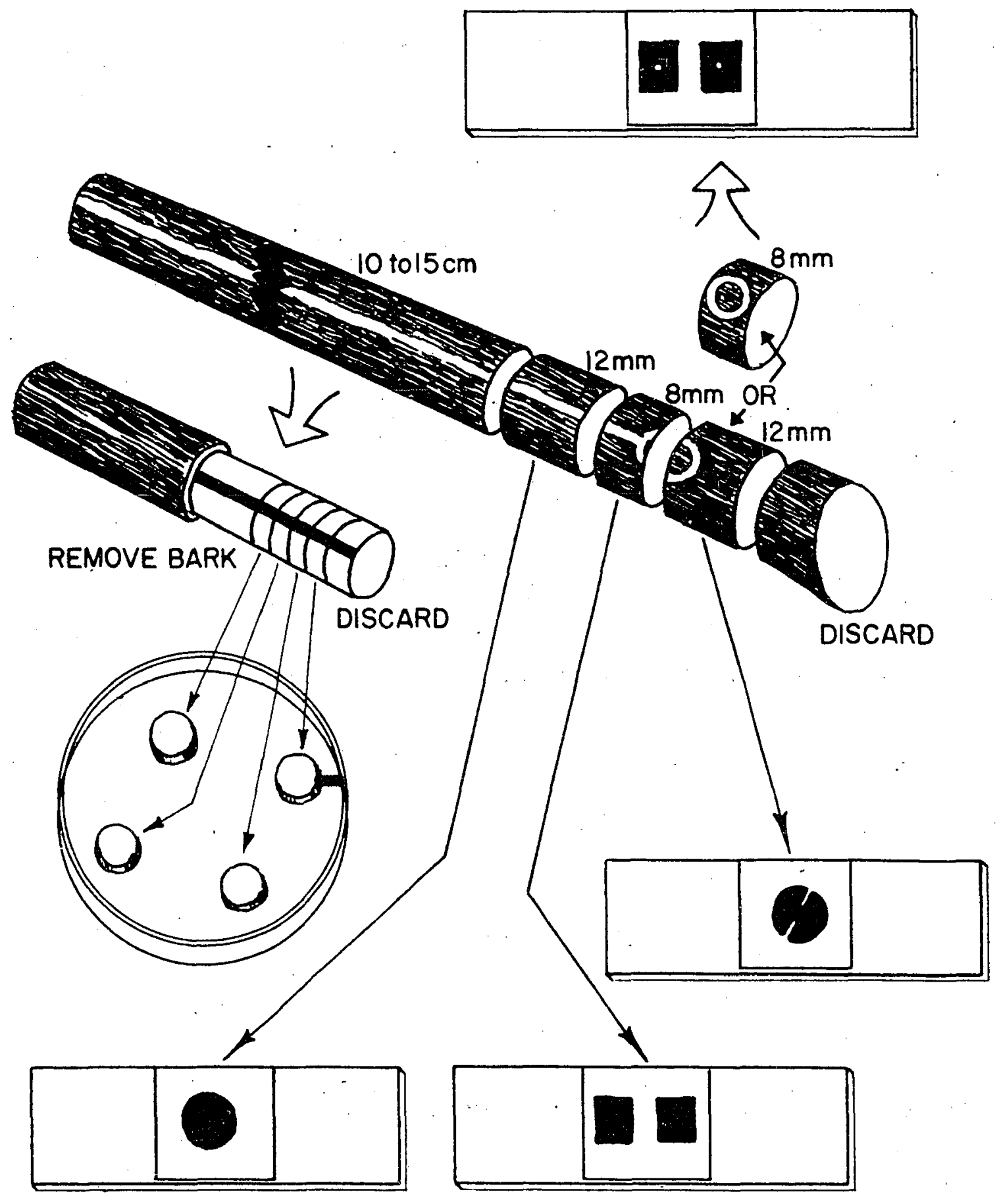
the procedures outlined above.

All. samples for culturing from a given branch were numbered, wrapped with the sketch of that branch in aluminum foil, appropriately marked and stored in a cooler for trans-. port to Ames.

\section{Modification of procedures - 1961 series}

For the 1961 series of inoculations several procedural modifications were made. A portable battery-powered drill was devised to facilitate inoculation (Figure 2). Glass syringes and steel needles were employed instead of the disposable polyethylene syringes and aluminum needles.

Starting 1 April 1961, four series of inoculations were made at three week intervals. Three inoculated branches and three check branches, drilled and injected with sterile distilled water on one side, and drilled only on the other side, were collected every two weeks for eight weeks after inoculation. Another sample of the same composition was collected 12 weeks after inoculation (Table 2).

In the 1961 series, drilled checks were not made on the same trees with inoculated branches. In addition, during each collection three untreated checks were cut from other bur oaks in the same locality as the treated trees.

Sampling procedures in 1961 for sectioning and culturing were similar to those used in 1960 except that individual 
Figure 2. Battery-powered drill with disposable mount and bit used for preparing inoculation courts in 1961, and finger-twist drill used in 1960 (4/5x) 

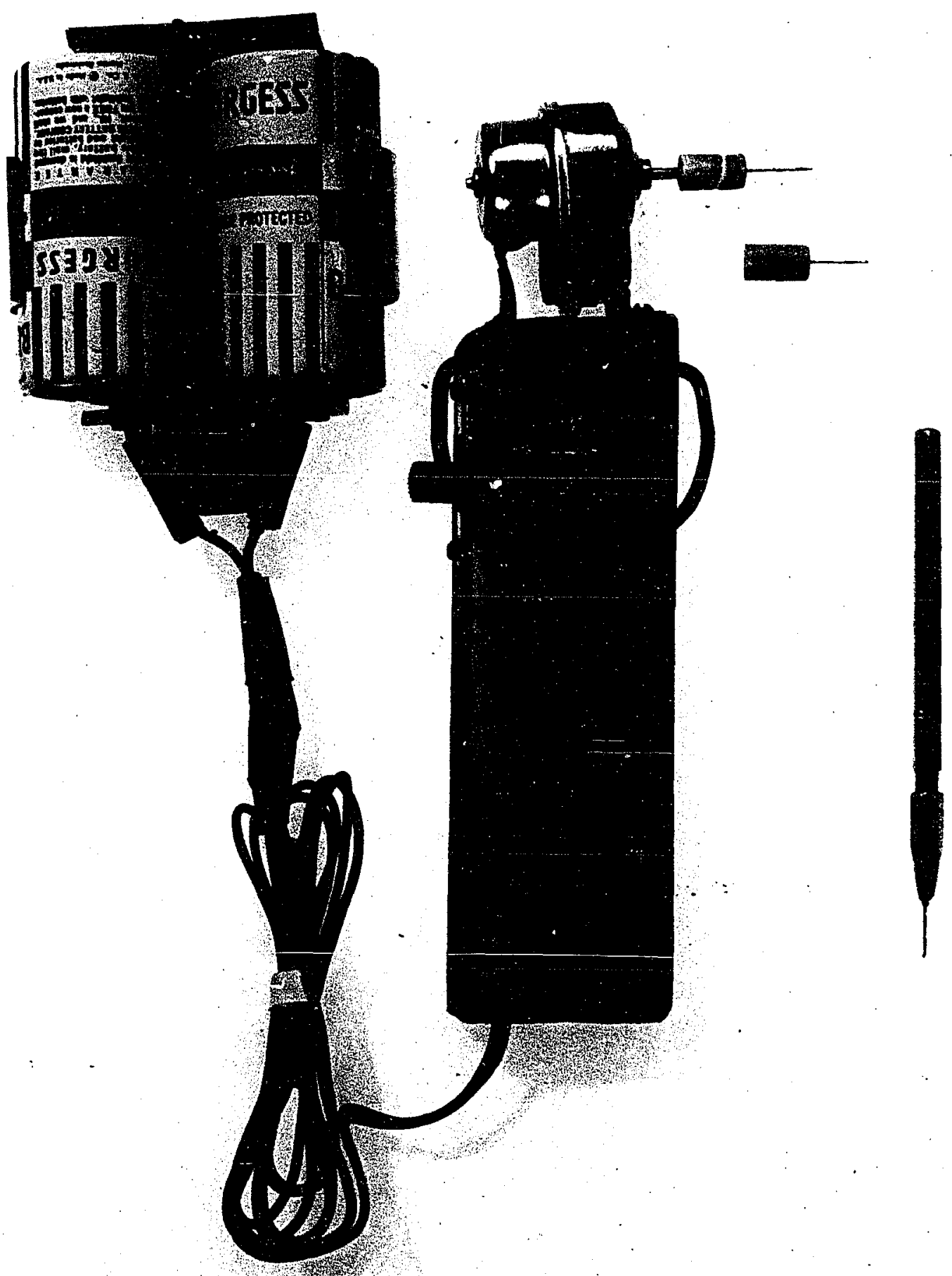
Table 2. Inoculation and sampling schedule for 1961 series of experiments on bur oaks in Pilot Knob State Park, Hancock County, Iowa

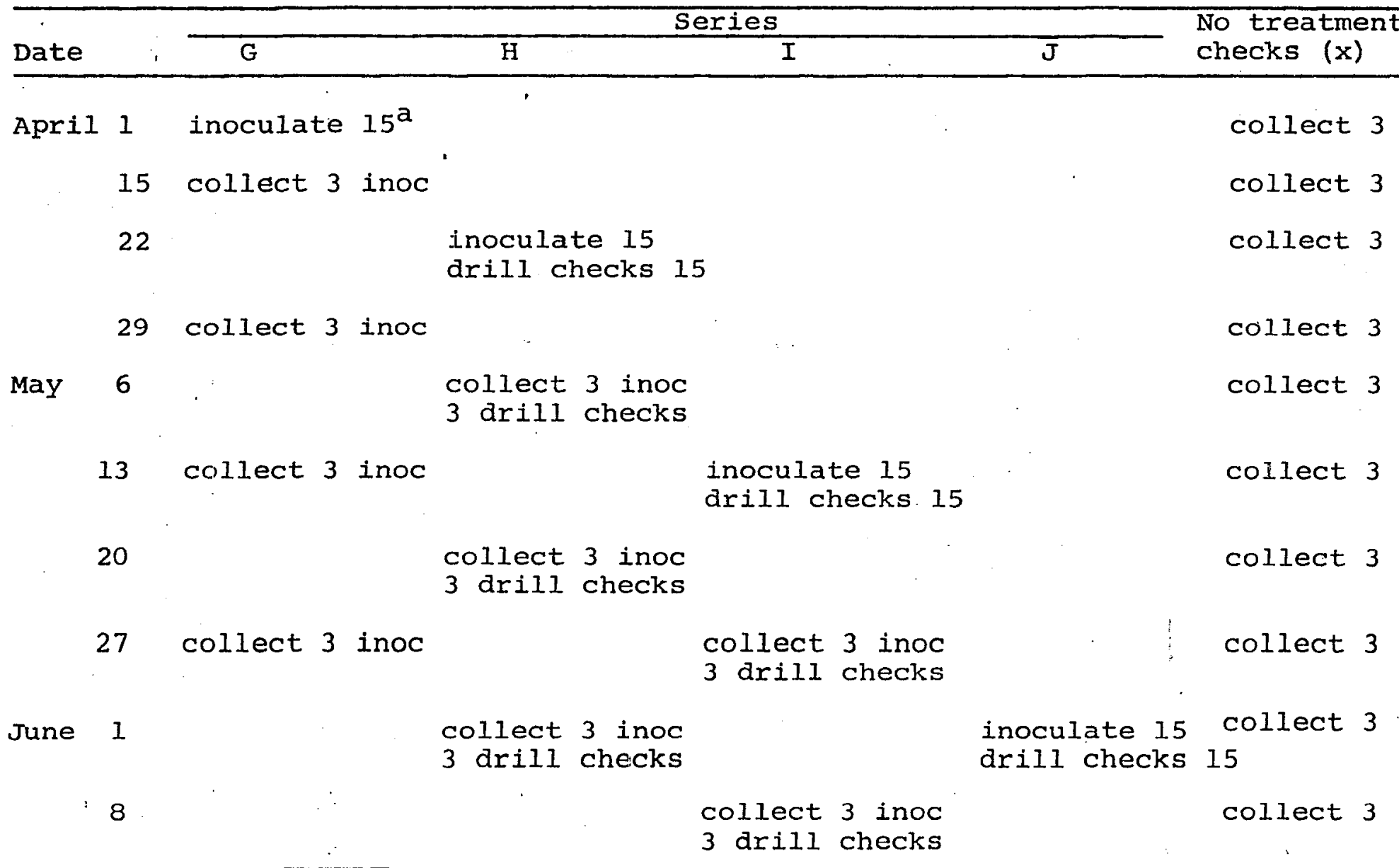

${ }^{a}$ Drill checks were omitted on I April 1961. Inoculum froze in needles. Heavy snow commenced, making working conditions too hazardous. 
Table 2. (Continued)

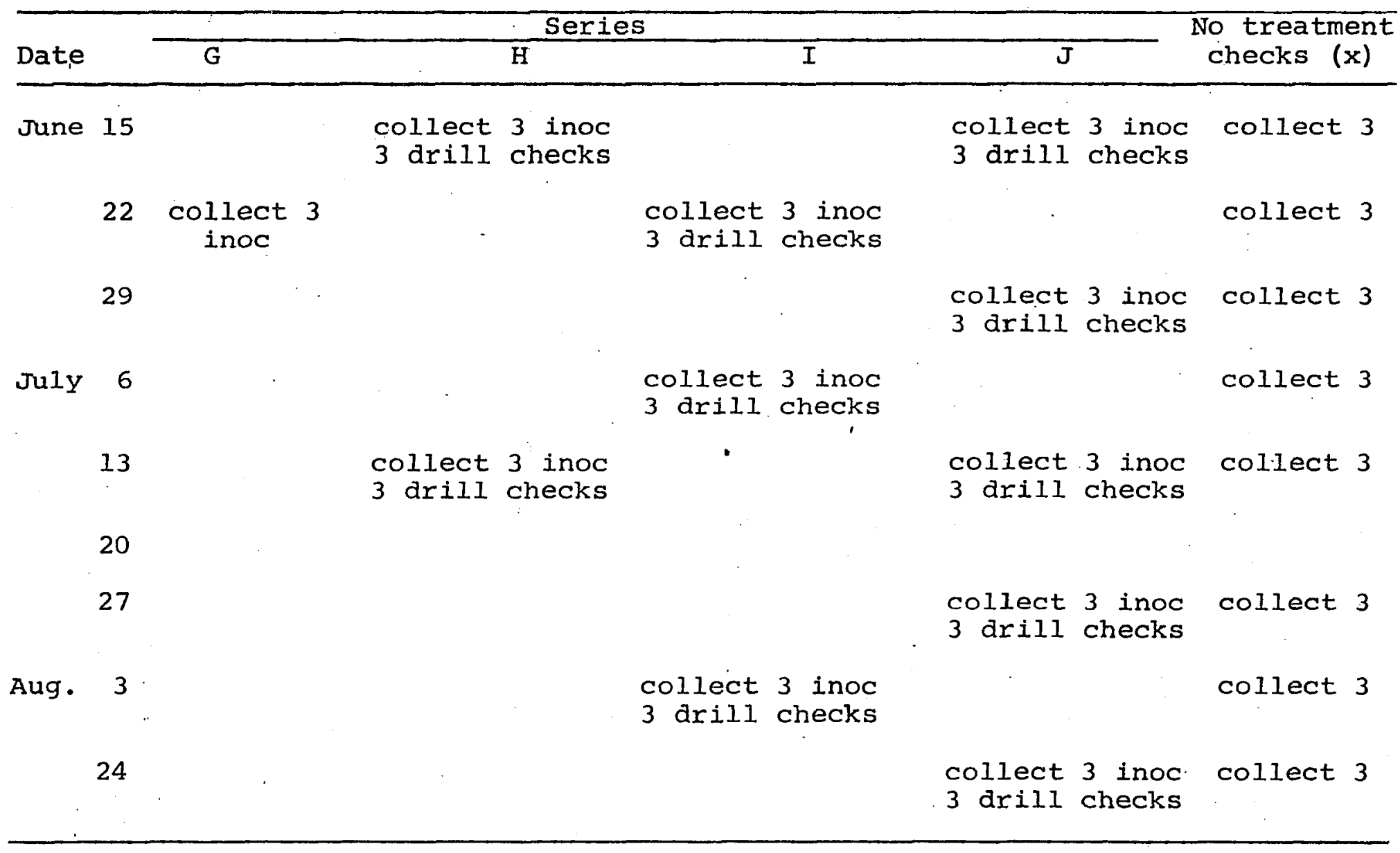


branches were not mapped. The distance of the various samples of a branch from the inoculation site and whether the samples were taken serially or from different forks were recorded in place of mapping.

Several measurements taken in 1960 were omitted for the 1961 series. The number of leaves on each branch were not recorded, since most leaves were not well expanded until May 20. Inside- and outside-bark diameter and age measurements were omitted.

\section{Isolation Technique}

A medium consisting of 0.5 percent potato dextrose 2 percent agar was used for culturing throughout the study. Enough bark was removed from the basal end of the sample to expose approximately five $\mathrm{cm}$ of wood. The reference line on the bark was reinscribed on the wood with a felt-tipped pen. A Masonite ${ }^{R}$ surface-was swabbed with alcohol; a pair of anvil-type cutters and the exposed portion of the branch were dipped in alcohol. Then all were set aflame. Five discs were cut from the sample, the first being discarded. Petri plates had been marked previously on the bottom with a reference line. Discs were placed in the plate serially, top-sideup, in clockwise order, with reference lines on the discs toward the reference line on the plate (Figure 1). Plates were labelled and incubated at $22-24^{\circ} \mathrm{C}$ for $12-14$ days. The 
sketches of the branches were redrawn and diagrams representing plates containing four discs were added. As plates were read the distribution of each isolate of $\underline{C}$. fagacearum was indicated in the plate diagrams.

A knowledge of the sectors in which the fungus was present would have been an aid in determining the orientation of samples for longitudinal sectioning. However, in most instances in which the pathogen emerged, it was impossible to determine the exact areas of initial emergence from the discs. That portion of the culturing procedure pertaining to alignment of the discs was discontinued during the 1961 series.

\section{E. Microtechnique}

Samples collected for microscopic studies were kept in FAA for at least one week. After killing they were transferred to 50-, 60- and 70 percent ethanol at daily intervals, and stored for sectioning in 70 percent ethanol. Prior to cutting, the samples were transferred again to 50 percent ethanol to reduce curling when sections were cut.

The material was not imbedded for cutting. A $250 \mathrm{~mm}$ knife mounted on a sliding microtome was used. Tangential sections through the cambial zone were cut usually $16 \mu$ thick, and occasionally as thin as $12 \mu$. Tangential sections in the xylem were cut between 22 and $26 \mu$ in an attempt to avoid 
losing any hyphae that may have been present. Transverse sections were cut from each sample at 20 to $36 \mu$.

The sectioned material was hydrated. Sections through the cambial zone were stained with iron hematoxylin for one hour after having been in iron-alum mordant for one hour. These were destained to the desired intensity in a half-andhalf mixture of mordant and saturated aqueous picric acid. other longitudinal sections and transverse sections were stained for 40 minutes in self-mordanting hemalum and 30 minutes in one-half percent aqueous safranin 0 . After. appropriate washings, the sections were transferred to 30 percent ethanol in two steps. The sections were mounted in glycerin directly from the 30 percent ethanol.

After a few weeks the glycerin medium was considerably tinted with safranin diffusing from the sections, usually making microscopic study uncomfortable, if not difficult. A green filter alleviated the difficulty satisfactorily.

For observations pertaining to starch accumulations, unstained sections were immersed for a few minutes in an $I_{2}-K I$ solution.

If a section appeared to be especially illustrative, it was remounted permanently. The glycerin-mounted slide was submerged in anhydrous ethanol; the cover glass was lifted and the section swirled lightly. The section was transferred to fresh anhydrous ethanol, and then run through a series of 
ethanol-xylene mixtures to pure xylene. After another transfer of xylene the section was mounted in a synthetic resin. (Sass 1951) 


\section{RESULTS}

\section{A. Frequency and Distribution of oak Wilt among Inoculated Branches}

In 1960, branches of the same trees were either inoculated with spores of $\underline{C}$. Eagacearum or injected with water. only those water-injected branches that occurred on trees that ultimately succumbed to oak wilt became diseased. In 1961, water-injected check branches and inoculated branches were located on different trees. None of the 1961 check branches exhibited foliar symptoms or yielded $\underline{C}$. fagacearum in culture.

The incidence of successful inoculations appeared very low; 293 out of 348 inoculated branches neither developed foliar symptoms of the disease nor yielded $\subseteq$. fagacearum in culture (Figure 3). The success obtained in attempts to reisolate $\underline{C}$. fagacearum from diseased branches was poorer than expected. The inciting organism was isolated from 28 of the 50 inoculated branches that developed foliar symptoms. Seven of the remaining 22 branches were dead at the time of collection and therefore were not likely to have yielded $\underline{C}$. fagacearum, regardless of the isolation technique used.

other fungi and bacteria were isolated consistently from bur oak branches, regardless of treatment. Less than three percent of approximately.1100 plates contained wood discs with no emergent microflora. Except on rare occasions, the oak 


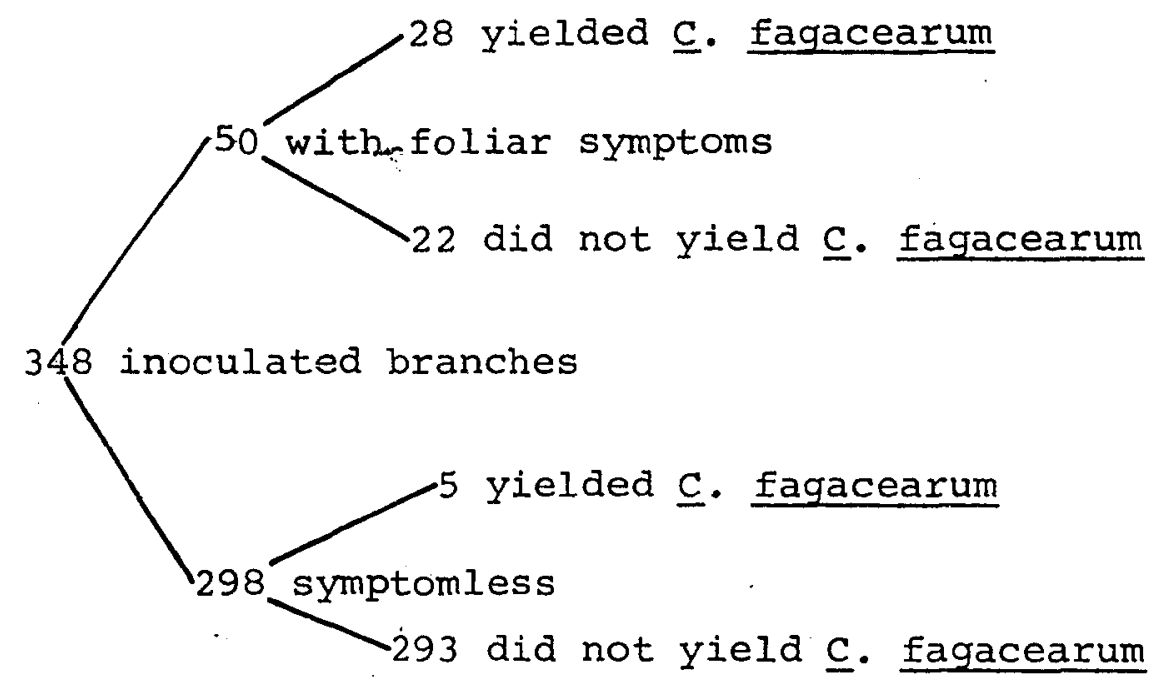

Figure 3. Frequency of foliar symptoms of oak wilt and of recovery of $C$. fagacearum from inoculated bur oak branches of 1960 and 1961 series of experiments conducted at Pilot Knob State Park, Hancock County, Iowa

wilt organism and any other microorganisms appeared mutually exclusive in any given branch disc.

The form-genera most commonly encountered among the fungal contaminants were Trichoderma, Phomopsis, Phoma, Coniothyrium and Alternaria. All of the above contaminants grew more rapidly than $\underline{c}$. fagacearum and all except Alternaria usually covered the wood discs within the first week of incubation.

Only occasionally were hyphae observed in sectioned material from branches inoculated with $\subseteq$. fagacearum. Because of the apparent absence of fruiting structures, it was impossible to determine whether the hyphae observed were of 
C. Eagacearum or of one of the contaminants. $\underline{\text {. }}$ fagacearum was recovered consistently from several branches in which hyphae were observed in vessels (Figures 4 and 5).

Hyphae were not observed in sectioned material from water-injected branches or untreated branches.

As might have been expected, the frequencies of symptom expression and recovery of $\underline{C}$. fagacearum increased as the period between inoculation and collection increased (Table 3 ). In 40 of the 55 branches developing symptoms, yielding the fungus or both, symptoms or recovery of the fungus were first noted between four and eight weeks after inoculation. ‥ fagacearum was recovered from branch $10 \mathrm{~B}$ one week after inoculation. Branches $40 \mathrm{C}$ and $2 \mathrm{~J}$ developed slight foliar symptoms within two weeks after inoculation.

Two branches that were inoculated on 21 July 1960 developed no foliar symptoms until the following July. The albino isolate was isolated from both branches. None of the other inoculated branches on the tree had developed symptoms before they were collected. However by 20 July 1961 the upper crown of the tree had-developed moderately severe foliar symptoms of oak wilt.

Generally, the data indicated branches were more susceptible to infection between the middle of May and late June or early July than before or after that period (Table 3). of the 55 branches that were considered successfully inoculated 
Figure 4. Cross section of a sample from an inoculated bur oak branch which yielded $\underline{C}$. fagacearum consistently, showing hyphae in diseased vessels (240x)

Figure 5. Tangential section of a sample from same branch as above showing hyphae in diseased vessels (240x) 

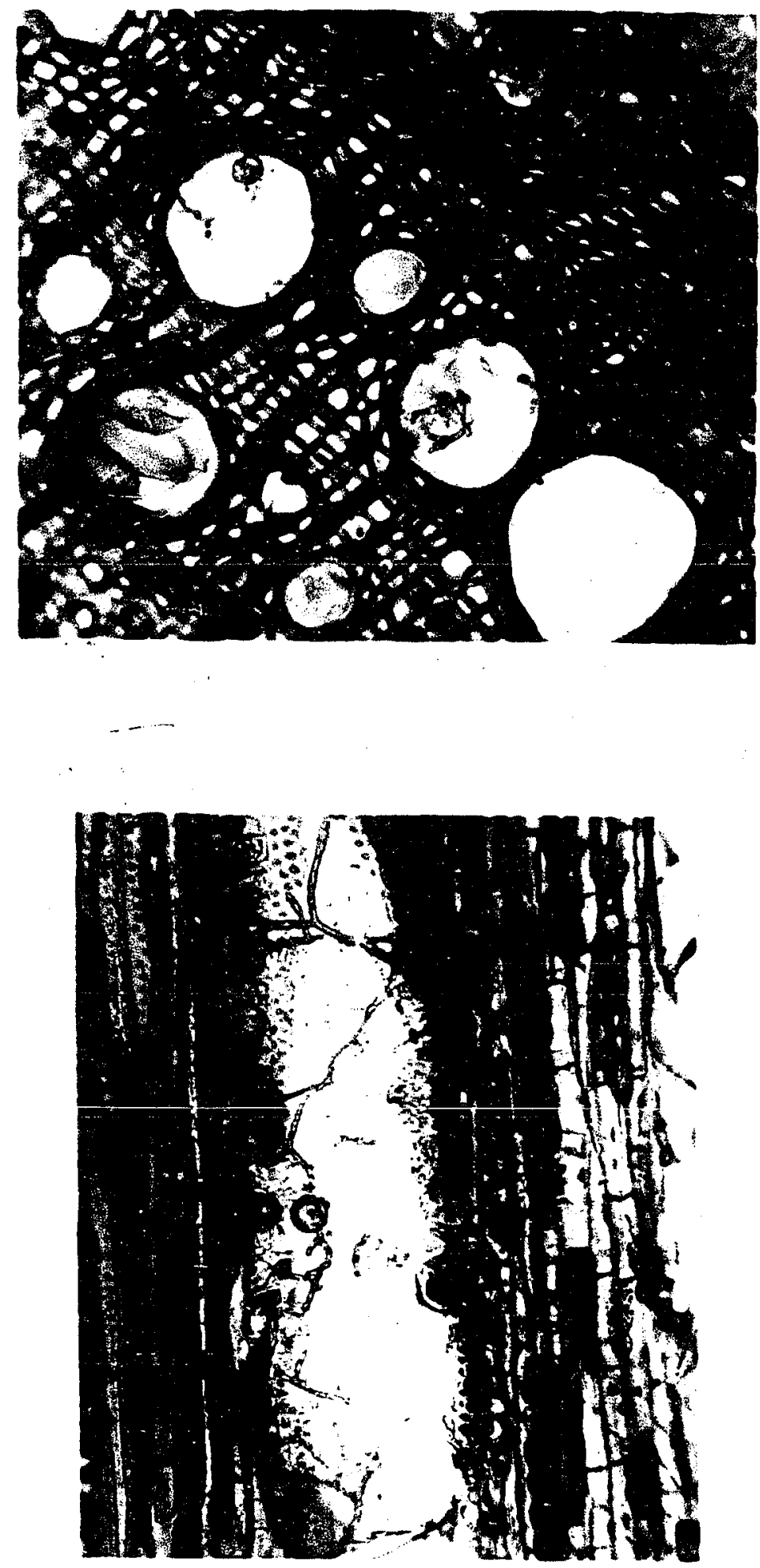
Table 3. Weeks after inoculation of first observations of foliar symptoms on bur oak branches inoculated with C. fagacearum on various dates during 1960 and 1961, Pilot Knob State Park, Hancock County, Iowa

\begin{tabular}{|c|c|c|c|c|c|c|c|c|c|c|c|}
\hline \multirow{2}{*}{$\begin{array}{l}\text { Weeks } \\
\text { after } \\
\text { inoc. }\end{array}$} & \multicolumn{3}{|c|}{ Inoc. date } & \multicolumn{3}{|c|}{1960} & \multicolumn{5}{|c|}{1961} \\
\hline & $\begin{array}{c}A \\
6-9\end{array}$ & $\begin{array}{c}B \\
6-23\end{array}$ & $\begin{array}{c}C \\
7-7\end{array}$ & $\begin{array}{c}D \\
7-21\end{array}$ & $\begin{array}{c}E \\
8-4\end{array}$ & $\underset{8-18}{F}$ & $\begin{array}{c}G \\
4-1\end{array}$ & $\begin{array}{c}\mathrm{H} \\
4-22\end{array}$ & $\begin{array}{c}I \\
5-13\end{array}$ & $\underset{6-1}{J}$ & $\Sigma$ \\
\hline 1 & & & & & & & & & & & \\
\hline 2 & & & 1 & & & & & . & & 1 & \\
\hline 3 & & 2 & & 1 & & 1 & & & & 6 & 10 \\
\hline 4 & & 3 & 5 & 1 & & & & & & 2 & $1:$ \\
\hline 5 & 1 & 2 & & & & & & & & & \\
\hline 6 & & 5 & & & 2 & & & • & 7 & & 12 \\
\hline 7 & 2 & 3 & 1 & & & & & & $=$ & & \\
\hline 8 & & & & & & & & 1 & & & \\
\hline$>8$ & & & 1 & 2 & & & & & & & \\
\hline$\Sigma$ & $\overline{3}$ & $\overline{15}$ & $\overline{8}$ & $\overline{4}$ & $\overline{2}$ & $\bar{I}$ & $\overline{0}$ & $\vec{I}$ & $\overline{7}$ & $\overline{9}$ & \\
\hline
\end{tabular}

No. inoc, each series

$\begin{array}{lllllllllll}48 & 48 & 48 & 48 & 48 & 48 & 15 & 15 & -15 & 15\end{array}$
348

by virtue of foliar symptom development or recovery of $\underline{c}$.

fagacearum, 47 were inpculated either between 9 June and 7 July 1960 or between 13 May and 1 June 1961.

of the 44 trees used for inoculations in 1960, two were dead in the spring of 1961 and four had developed moderate to severe symptoms of oak wilt in their upper crowns.

The inoculations made on 23 June 1960 were the most suc- 
cessful of that year (Table 4). Trees 8, 9, 10, and 11 were within 100 feet of each other and were similar with respect to size and position in the forest canopy. Yet the distribution of infected branches was not uniform. Tree 8 was dead by the spring of 1961, Trees 10 and 11 developed no new symptoms in 1961, and Tree 9 never developed foliar symptoms of oak wilt.

Table 4. Distribution of diseased bur oak branches inoculated on 23 June 1960 among trees, and recurrence of symptoms on the trees in 1961, Pilot knob state Park, Hancock County, Iowa

\begin{tabular}{cccl}
\hline Tree & $\begin{array}{c}\text { No. branches } \\
\text { inoc. }\end{array}$ & $\begin{array}{c}\text { No. } \\
\text { diseased }\end{array}$ & $\begin{array}{c}\text { Symptoms on trees } \\
\text { in } 1961\end{array}$ \\
\hline 8 & 10 & 7 & dead \\
10 & 6 & 0 & none \\
11 & 10 & $3^{a}$ & none \\
14 & 8 & $3^{b}$ & $\begin{array}{l}\text { staghead; } \\
\text { no new foliar } \\
\text { symptoms }\end{array}$ \\
15 & 9 & $1^{\mathrm{C}}$ & $\begin{array}{l}\text { none } \\
\text { ntaghead; } \\
\text { no new foliar } \\
\text { symptoms }\end{array}$ \\
\hline
\end{tabular}

ane branch, collected in summer of 1961, neither yielded c. fagacearum in culture nor developed recurrent foliar symptoms.

${ }^{b}$ one branch, collected in summer of 1961, yielded $\mathrm{C}$. fagacearum in culture, but developed no recurrent foliar symptoms.

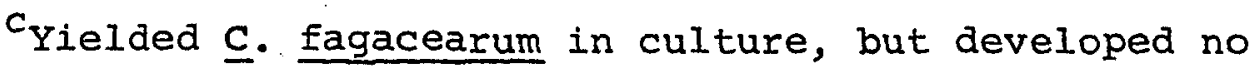
foliar symptoms. 
Trees 14 and 15 were nearly side-by-side in a different area than the other four trees. Tree 14, with nine inoculated branches, remained symptomless as of 24 september 1961. Five branches of Tree 15 were inoculated. Three of these five branches developed symptoms and yielded $\underline{c}$. fagacearum, and the upper crown was severely wilted in early August 1960. Tree 15 was stag-headed in 1961, but no recurrence of foliar symptoms was observed.

The branches inoculated on 1 April 1961 neither yielded c. fagacearum nor exhibited foliar symptoms. During the inoculation procedure, the inocula were subjected to rapid changes in temperature, since the suspensions froze in the needles and had to be thawed to be injected. Therefore, the viability of the inoculum was questionable. However, it was noted that Tree 45, inoculated on that date, had developed severe symptoms of oak wilt by the middle of July. Four branches from various heights and aspects of the tree were cultured and all yielded a gray isolate of $\mathrm{c}$. fagacearum. When these cultures were cross-spermatized with cultures of the originai gray isolate, no perithecia were produced, indicating the isolate obtained from Tree 45 and the original isolate were of the same compatibility type. Consequently, it cannot be proved whether or not Tree 45 became infected naturally or as the result of artificial inoculation of its branches. None of the other trees inoculated on 1 April 1961 
developed foliar symptoms by 24 september 1961.

Of the 15 branches inoculated on 22 April 1961, one branch on Tree 50 showed symptoms two months later and yielded C. fagacearum. Although no other inoculated branches yielded the fungus or developed symptoms, Tree 50 was severely wilted by the midale of July.

Branches of three trees were inoculated on 13 May 1961. Nine of the 15 branches inoculated exhibited foliar symptoms, yielded the fungus, or both. All three trees were severely wilted by the first or second week in July. One of the three trees was inoculated in only one branch: The branch itself, collected two weeks after inoculation neither developed symptoms nor yielded $\underline{c}$. fagacearum. No isolations were attempted from the wilted crowns of these trees.

on I June 1961, branches of two trees were inoculated. on the first tree nine out of ten inoculated branches showed symptoms or yielded the fungus, or both. on the other tree, approximately 40 feet away, none of the five inoculated branches showed symptoms or yielded $\subseteq$. Eagacearum.

Certain trees appeared to have been preferentially susceptible to one or the other: isolate (Table 5). C. fagacearum was isolated from two or more branches of eight trees. Generally, all the branches from the same tree yielded the same isolate. No branch yielded both isolates. on all trees there were several to many uninoculated 
Table 5. Distribution of isolates of $\mathrm{C}$. fagacearum among inoculated branches of 14 bur oaks in Pilot Knob State Park, Hancock County, Iowa

\begin{tabular}{lcccc}
\hline Tree & $\begin{array}{c}\text { Inoculation } \\
\text { date }\end{array}$ & $\begin{array}{c}\text { No. branches } \\
\text { yielding } \\
\text { fagacearum }\end{array}$ & Gray & White \\
\hline 2 & $6-9-60$ & 1 & 0 & 1 \\
6 & $6-9-60$ & 1 & 1 & 0 \\
13 & $6-9-60$ & 1 & 0 & 1 \\
8 & $6-23-60$ & 4 & 4 & 0 \\
11 & $6-23-60$ & 3 & 0 & 3 \\
14 & $6-23-60$ & 1 & 0 & 1 \\
15 & $6-23-60$ & 3 & 3 & 0 \\
22 & $7-7-60$ & 2 & 0 & 2 \\
24 & $7-7-60$ & 1 & 0 & 1 \\
29 & $7-21-60$ & 2 & 0 & 2 \\
50 & $4-22-61$ & 1 & 1 & 0 \\
54 & $5-13-61$ & 5 & 4 & 1 \\
55 & $5-13-61$ & 2 & 0 & 2 \\
60 & $6-1-61$ & 6 & $\frac{2}{15}$ & 18 \\
\hline 14 & & 33 & & 4 \\
\hline
\end{tabular}

branches interspersed among those selected for treatments. Most were rejected because of undesirable size, shape or defects. Inoculated branches developed symptoms one to three weeks before any uninoculated branches on the same tree, except on Tree 60. In this exception, foliar symptoms on 
uninoculated branches of the upper crown and on two inoculated branches were first noted on the same date.

B. Internal Reactions to Infection by $\underline{C}$. fagacearum

Tylosis formation preceded the appearance of foliar symptoms. Sometimes tyloses proliferated into froth-like masses (Figure 6). Usualiy gum deposits and tyloses did not occur together, but occasionally spaces among tyloses were filled with gums.

Seasonal fluctuations of accumulated starch in xylem of healthy and diseased bur oak branches were observed between 1 April and 24 August 1961. From I April until late May, nearly all living pith, ray and xylary parenchyma were completely filled with amyloplasts. In samples collected on 27 May, a discernible decrease in starch content was noted in the ray parenchyma although there appeared to be abundant starch in the pith and xylary parenchyma.

In samples collected on 1 June amyloplasts were found rarely in ray cells, and were less numerous in xylary and pith parenchyma. Almost no amyloplasts were observed in pith, rays or xylary parenchyma of branch samples collected on 15 June.

Starch began to accumulate again in late June, first in the xylary and pith parenchyma and then in the ray cells. In samples collected on 6 July, amyloplasts were abundant 
Figure 6. Froth-like proliferation of tyloses in diseased

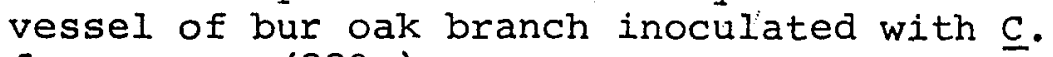
fagacearum $(880 \mathrm{x})$ 


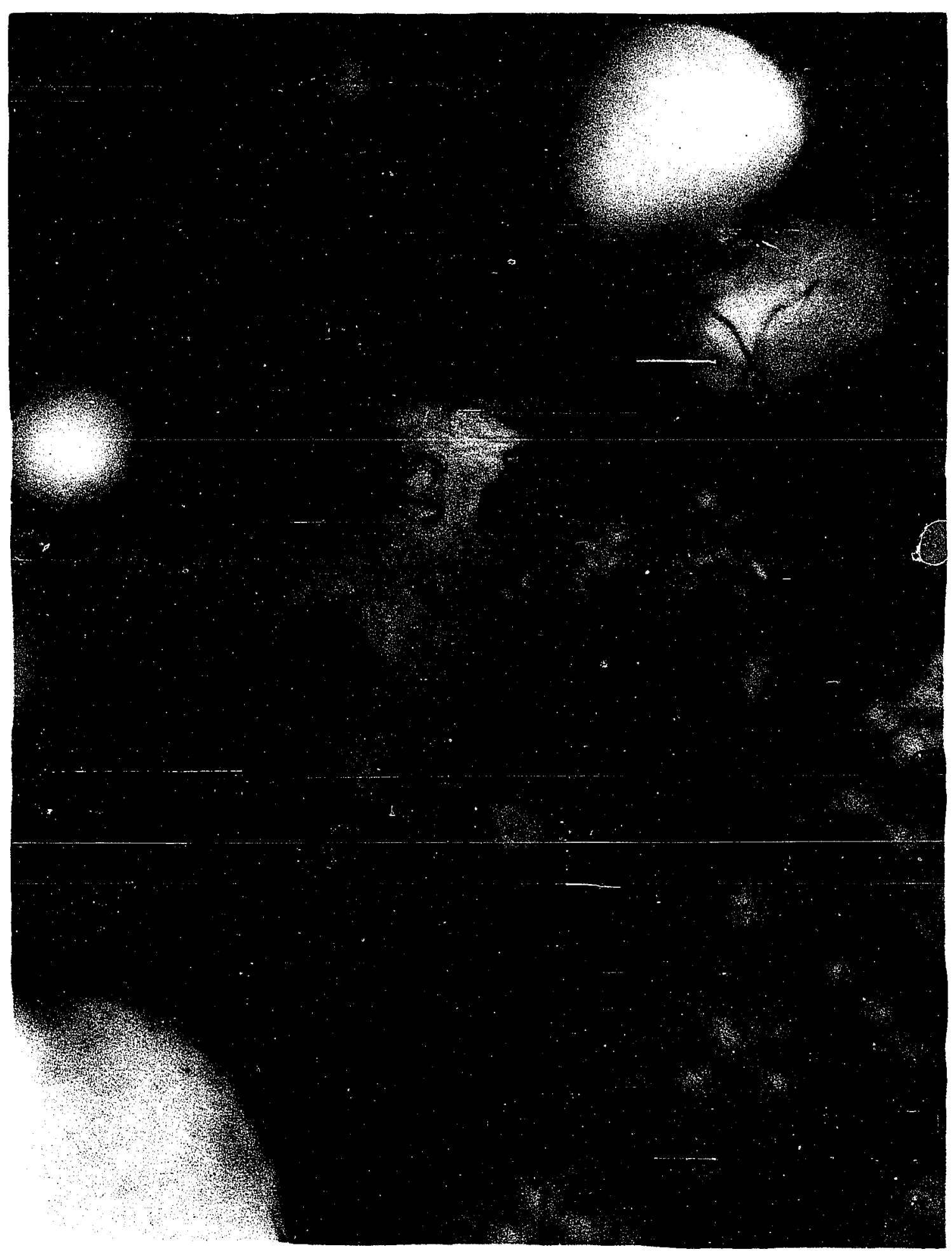


in the xylary parenchyma and slightly less abundant in pith and ray parenchyma. By 13 July, all uninjured xylary and medullary parenchyma were filled with amyloplasts.

The accumulation of starch in infected branches appeared to be similar to that in uninfected branches sampled on the same day, except in those parts of the outer two rings tylosed and gummosed as a result of the disease. Even branches in advanced stages of wilt and defoliation contained apparently normal accumulations of starch in uninfected parts. However, all wilt-killed branches, regardless of when they died, were devoid of starch. Most of the parenchymatous xylary cells of wilt-killed branches contained varying quantities of gums (Figures 7, 8, 9 and 10). Except for the vessels in infected parts of the outer two annual rings, most of the vessels of wilt-killed branches appeared free of occlusions (Figure 9).

A phenomenon similar to double-banding in wilt-diseased white oaks (․ $\underline{\text { alba) }}$ was observed in 27 inoculated bur oak branches. Production of wilt-induced tissue was initiated in branches inoculated as early as 22 April 1961, and as late as 4 August 1960. Double-band formation was detected two weeks after inoculation in branch $40 \mathrm{C}$, on which only a cluster of four leaves had developed symptoms. Sectors of wilt-induced vascular tissue were observed in two branches on which no foliar symptoms of oak wilt had developed. Symptomatic 
Figure 7. Bur oak branch IlB killed by oak wilt, doubleband initiation $(A)$, and gummosis of ray and xylary parenchyma; stained with hemalum and safranin $0(95 x)$

Figure 8. Healthy bur oak branch showing starch accumulation in ray and metatrachial xylary parenchyma; stained with $I_{2}-K I(95 x)$ 

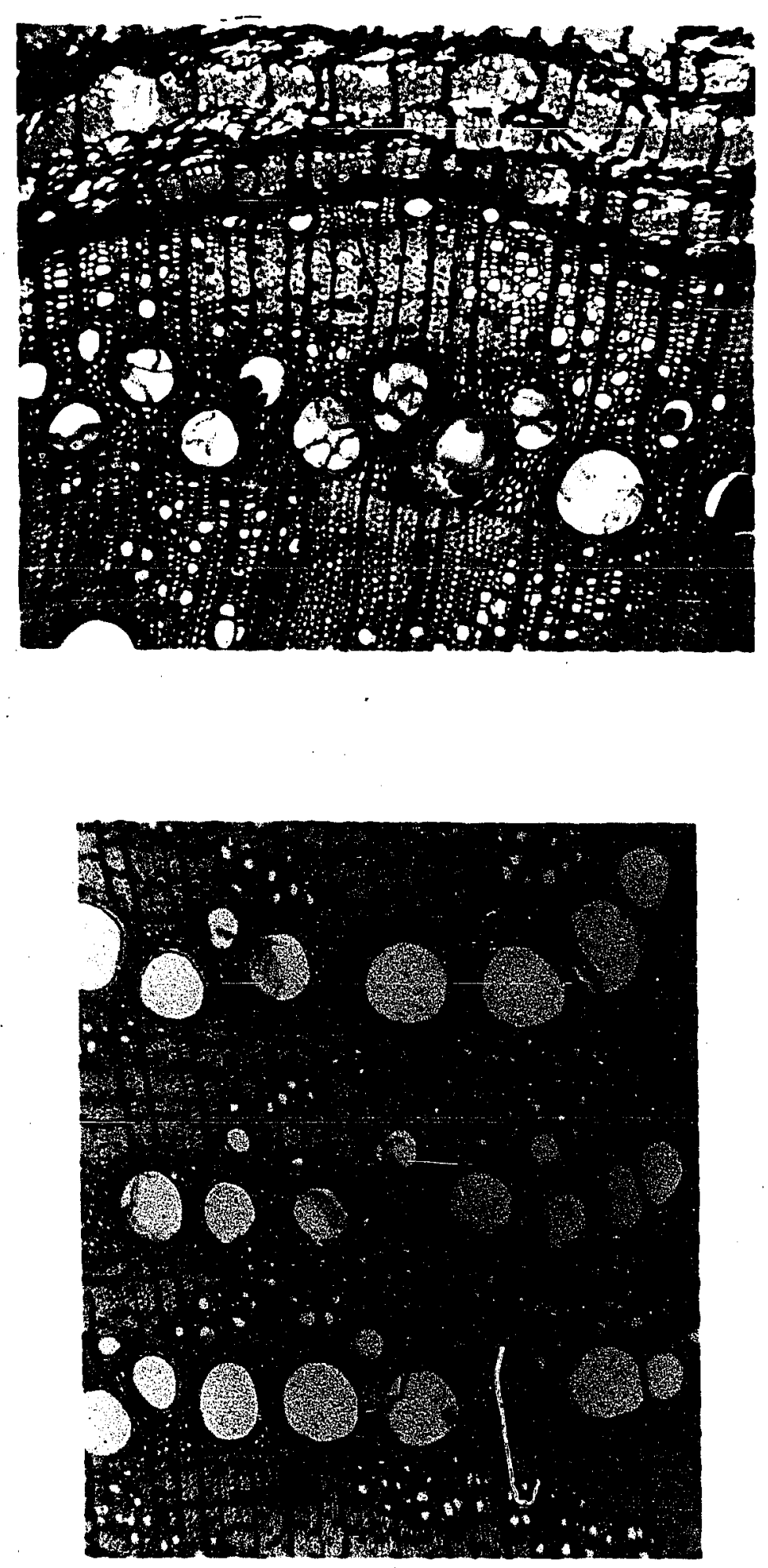
Figure 9. Bur oak branch 11B, killed by oak wilt, showing gummosis of pith cells and ray parenchyma; stained with hemalum and safranin 0 ; note the scarcity of gums and tyloses in older vessels (5x)

Figure 10. Healthy bur oak drill-check branch containing large deposits of starch in pith, ray and xylary parenchyma, stained with hemalum and safranin 0 ; the starch was not stained, compare the conspicuousness of gummosed (Figure 9) and starchfilled pith and ray parenchyma (5x) 

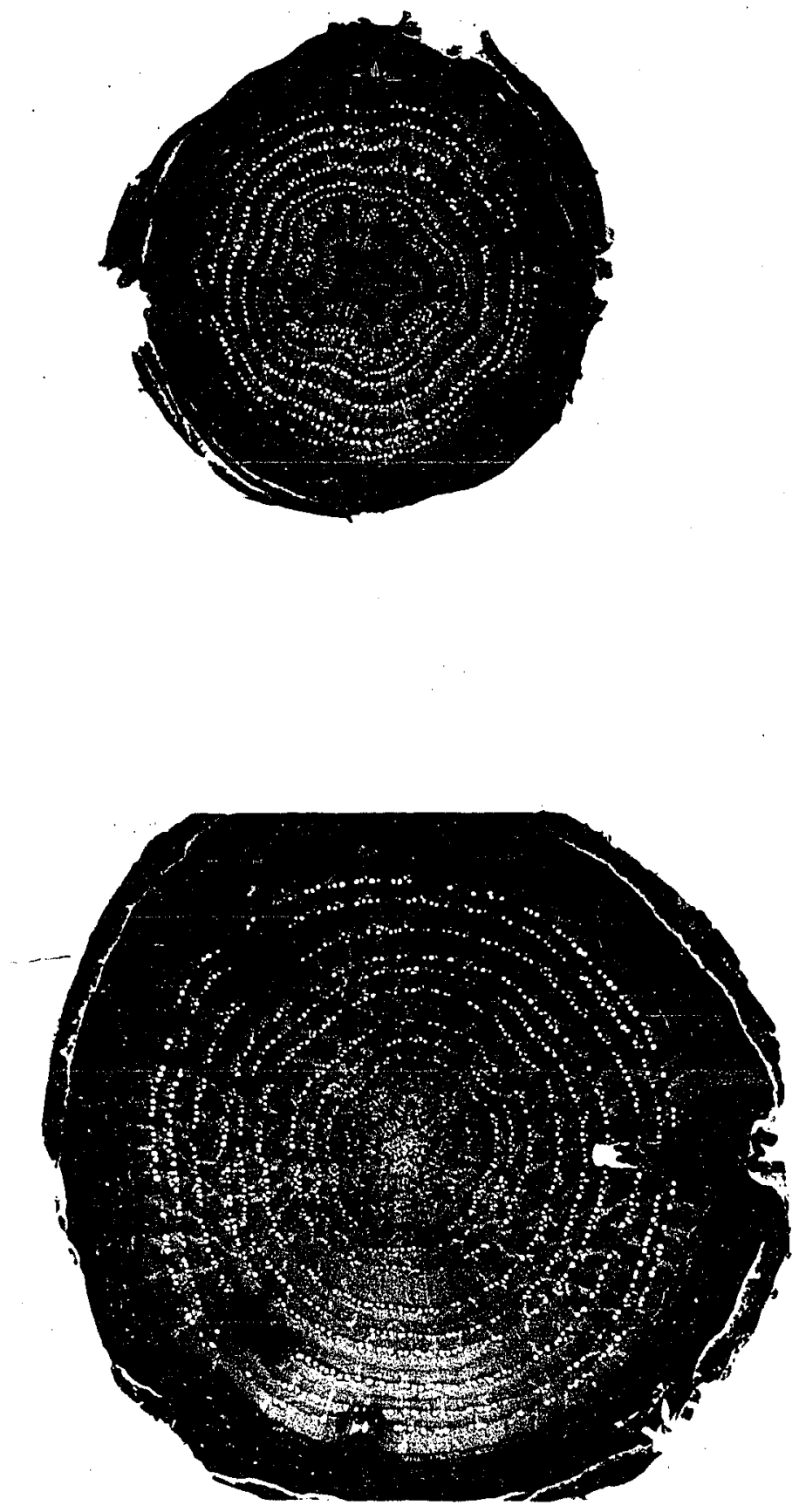
tyloses were observed in both branches, and $\underline{C}$. Eagacearum was recovered from one. Double-banding was observed in several branches that were killed by oak wilt (Figure 7) .

In uninfected bur oak branches the latewood was composed mainly of thick-walled, heavily lignified fibers and more or less radially aligned flame-shaped zones of small vessels, vertical parenchyma cells, and tracheids. Usually one to several concentric rings (in cross section) of metatracheal parenchyma were produced in the latewood (Figure 8).

The wilt-induced portion of the double-band contained numerous uniformly scattered vessels, somewhat larger and less angular (in cross section) than typical latewood vessels. More tracheids and scattered parenchyma and fewer fibers were differentiated in the wilt-induced tissue than in typical latewood.

In most branches that developed foliar symptoms before July, the initiation of double-band formation occurred before any latewood had been produced. In all of the above branches at least one layer of vessels were mature at the time of collection. The conjunctive tissue between the earlywood vessels and the subsequently produced tissue was composed mainly of slightly enlarged undifferentiated cells. Within the undifferentiated tissue were a few lignified small vessels and an occasional lignified tracheid (Figure 11). The most advanced development of wilt-induced tissue 
initiated before differentiation of any latewood had occurred is illustrated in Figure 12. The walls of most of the cells between the infected earlywood vessels and the wilt-induced vessels were not lignified and had very little secondary thickening. Those cells among the wilt-induced vessels and near the cambium had thickened, lignified walls. Apparently cambial cell divisions were increased, at least temporarily, as a result of infections early in the growing season. The widths of the cambial zone were consistently greater in diseased sectors than in disease-free sectors of the same branch. The width of the cambial zone gave little indication of increased cambial activity resulting from infections later in the season. However, annual rings usually were wider in sectors in which double-banding had occurred, indicating increased cell division in diseased sectors.

The extent of double-band formation and the appearance of subsequent growth varied considerably. Branches $38 \mathrm{~B}$ and 5lB were inoculated on 23 June 1960, and both developed foliar symptoms of oak-wilt approximately four weeks later. The symptoms persisted on branch 5IB for the remainder of the growing season. Branch $38 \mathrm{~B}$ appeared free of foliar symptoms two weeks after they were first noted. Both branches were collected in the middle of June, 196.1.

In branch 51B almost all of the 1960 earlywood vessels were occluded. Isolated narrow bands of wilt-induced tissue 
Figure 11. Branch 11H, inoculated 22 April 61, collected $13 \mathrm{July} 61$; broad zone of undifferentiated xylary tissue with a few scattered lignified vessels (A) between the cambium (B) and diseased 1961 vessels $(36 x)$

Figure 12. Most extensive development of double-band response to early infection that was observed; again note thin-walled small cells between wilt-induced vessels (A) and diseased 1961 earlywood vessels $(60 x)$ 

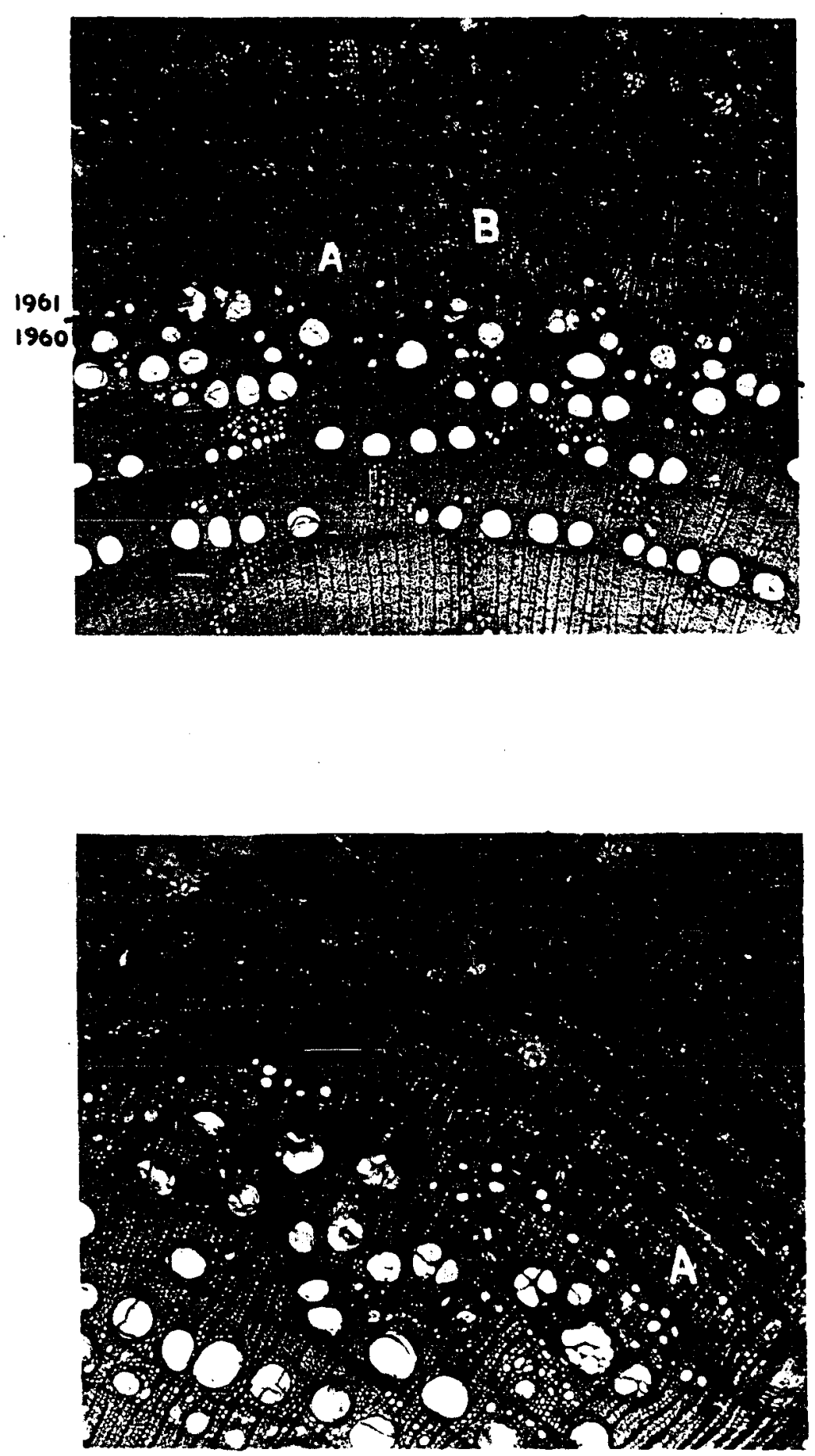
had been produced in 1960. New wood produced in 1961 contained vessels that were smaller, more numerous and more scattered than are typical of bur oak earlywood (Figures 13 and 14).

only one-fourth of the 1960 earlywood vessels of branch $38 \mathrm{~B}$ were diseased. A considerable amount of wilt-induced tissue was produced exterior to the diseased wood. The double-band narrowed down gradually to nothing beyond the limits of the diseased sector of 1960 wood (Figures 15 and 16).

Reversion toward diffuse porosity was evident in the new wood produced by branch 38B in 1961, especially in the segment of the branch including the diseased sector of the 1960 increment. The earlywood vessels produced in 1961 appeared considerably larger in diameter than those produced in previous years. Branch $38 \mathrm{~B}$ was younger and growing more rapidly than branch $51 \mathrm{~B}$.

When the method of isolation described in this study was

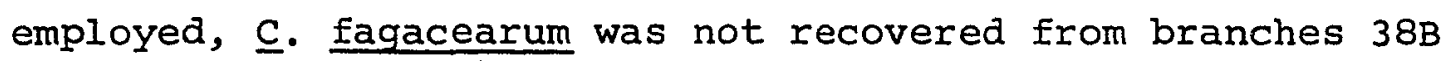
and 5IB. Contaminants from the wood were recovered. When the standard method of isolating from small chips was tried, $\underline{\text { c. }}$ fagacearum was recovered from both branches. Branch 5lB yielded the gray isolate, and branch $38 \mathrm{~B}$ the white isolate. Tree 11, on which branch 38B was located, was felled and sampled on 24 september 1961 in order to determine 
Figure 13. Section approximately two $\mathrm{cm}$ above inoculation sites on bur oak branch 5lB, inoculated 23 June 1960 , severely wilted by 28 July 1960 , free of foliar symptoms in 1961, collected 15 June 1961, development of a typically small earlywood vessels and reversion toward diffuse-porous arrangement in $196 I^{\circ}(A)$ and only slight development of wiltinduced tissue (B) in 1960 (60x)

Figure 14. Section of $51 \mathrm{~B}$ approximately $20 \mathrm{~cm}$ above inoculation sites, illustrating continuity of atypical tissues, 1961 xylem (A) and wilt-induced tissue (B) produced in 1960 (60x) 

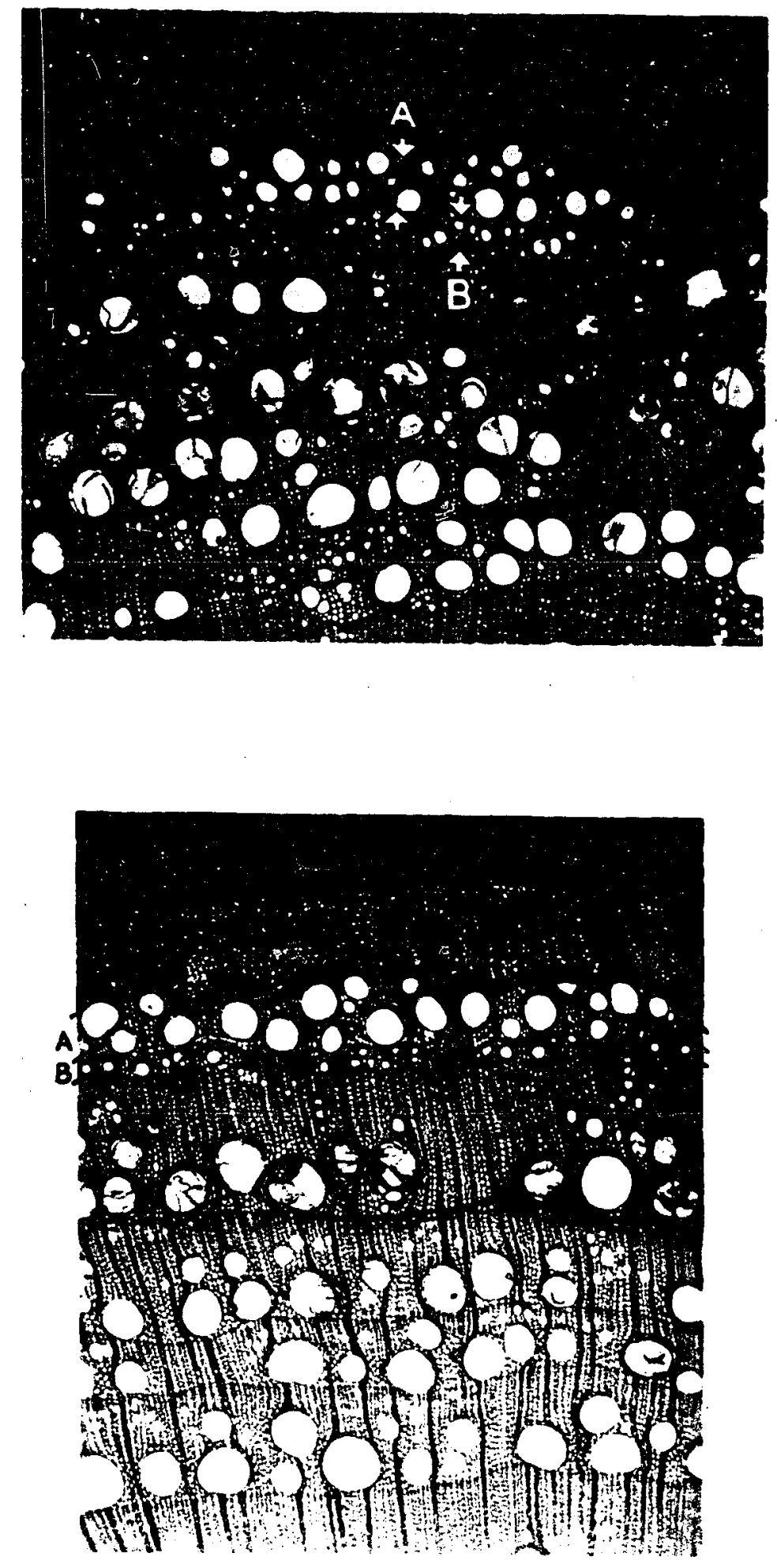
Figure 15. Part of section $50 \mathrm{~cm}$ above inoculation sites of bur oak branch 38B, inoculated 23 June 1960, slightly wilted 21 July 1960 , no foliar symptoms apparent after 4 August 1960, no symptoms in 1961, collected 22 June 1961; wilt-induced xylem (A) radially adjacent to diseased xylem (B): 1961 xylem diffuse-porous, 1961 earlywood vessels atypically large (36x)

Figure 16. Uninfected part of same section as shown above, with no development of double band; the diffuseporous arrangement of 1961 vessels is still evident (36x) 

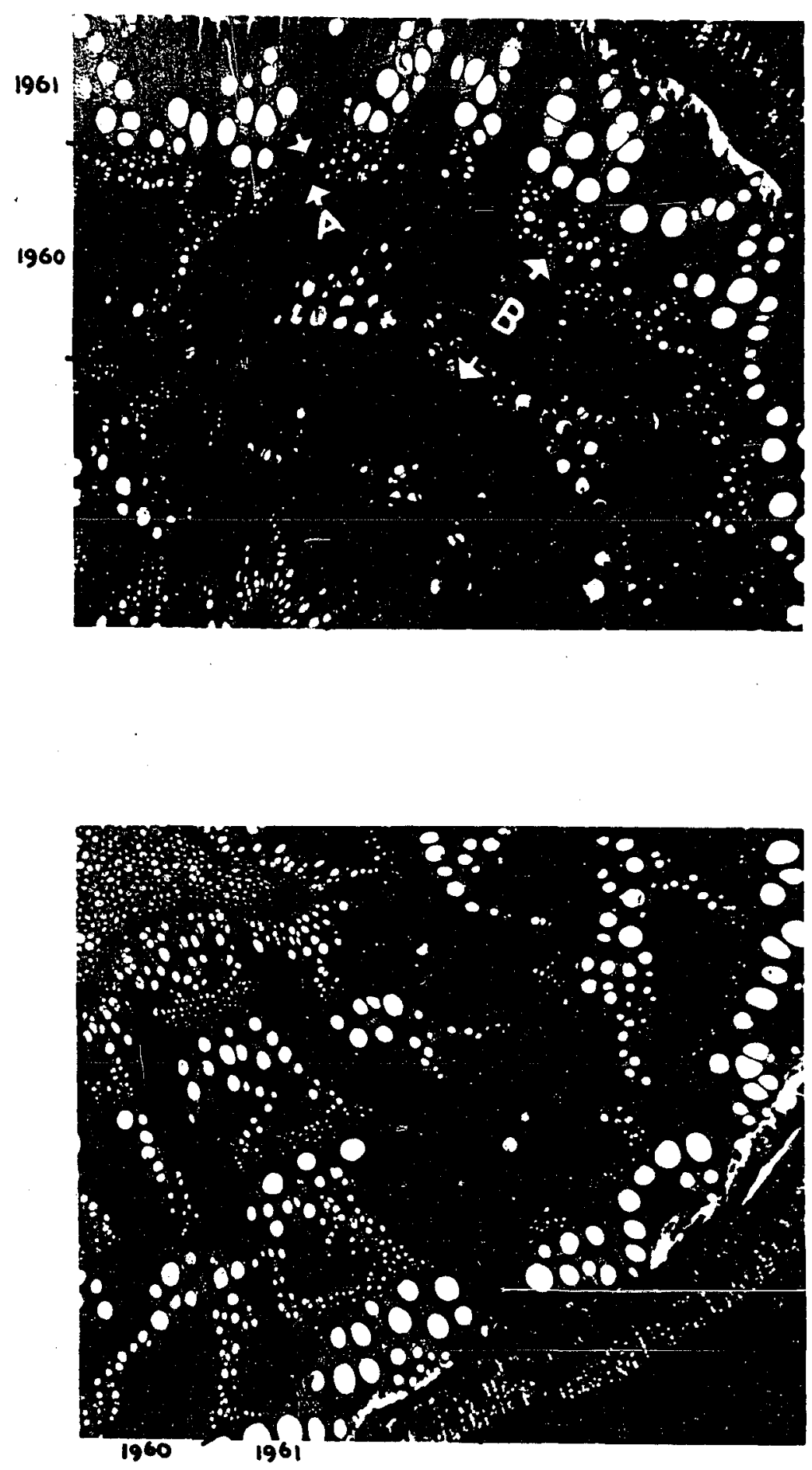
whether or not double-band formation occurred in the main stem. Parts of the vascular tissue produced in 1960 had become diseased, and double band formation had occurred. The 1961 increment appeared free of any symptoms of the disease (Figures 17 and 18).

It was noted that all the vessels of the main stem produced in years previous to 1960 were occluded with tyloses (Figure 17), whereas in the branches almost entire rings of vessels up to 15 years old were found free of occlusions. That only the outer one or two rings were functional in water conduction through the branches was demonstrated easily with water-soluble dyes.

Double-bands were observed in two branches which had received no experimental treatments. Branch $47 \mathrm{x}$ apparently had been infected with oak wilt in 1957, as indicated by double-banding (Figure 19). Branch 48x, according to the presence of double bands, had been infected with oak wilt in 1954, 1959 and 1960 (Figure 20). Both branches were col-

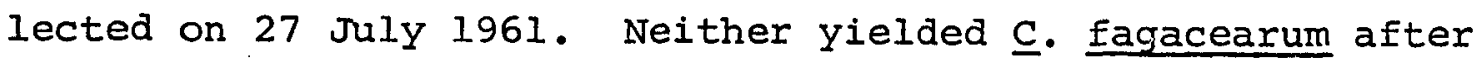
three attempts to isolate the fungus.

Cambial cell divisions were observed as early as 22 April in 1961 and as late as 15 October, the date on which the last collections in 1960 were made (Figures 21 and 22). In most of the observed instances, the plane of division was transverse to the axis of the tissue, regardless of the time 
Figure 17. Section of trunk of bur oak Tree 11, collected 24 September 1961, double-band formation in 1960 xylem; compare symptomatic tyloses in 1960 vessels with tyloses formed typically in vessels of older increments $(10 x)$

Figure 18. Close-up of outer two rings of Tree 11, symptomatic tyloses in 1960 earlywood, wilt-induced xylem (A), the amount of xylem produced in 1960 before double-band formation was initiated (B), and the disease-free 1961 xylem $(36 \mathrm{x})$ 

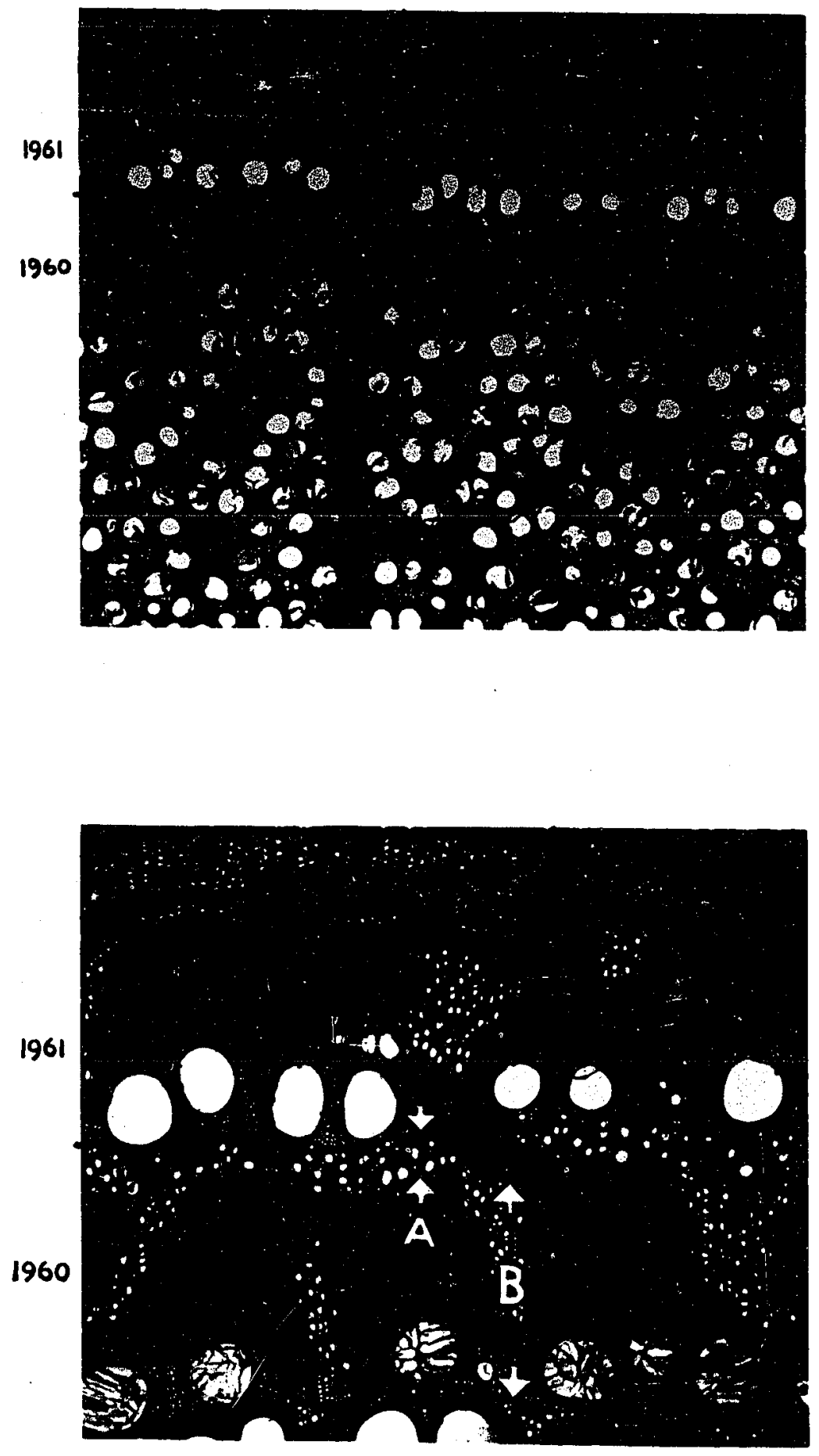
Figure 19. Bur oak branch $47 \mathrm{X}$ (no treatment; collected 27 July 1961, double-band formation (A) probably induced by oak wilt in 1957 (36x)
Figure 20. Bur oak branch $48 \mathrm{x}$ (no treatment) collected 27 July 1961, double-band formation probably induced by natural infection in 1954 (A) and 1960 (B) double-banding apparent.in parts of 1959 increment not shown in this photomicrograph; branches $47 \times$ (Figure 19) and $48 \mathrm{X}$ were on the same tree separated $20 \mathrm{~cm}$ vertically and approximately $130^{\circ}$ radially (36x) 

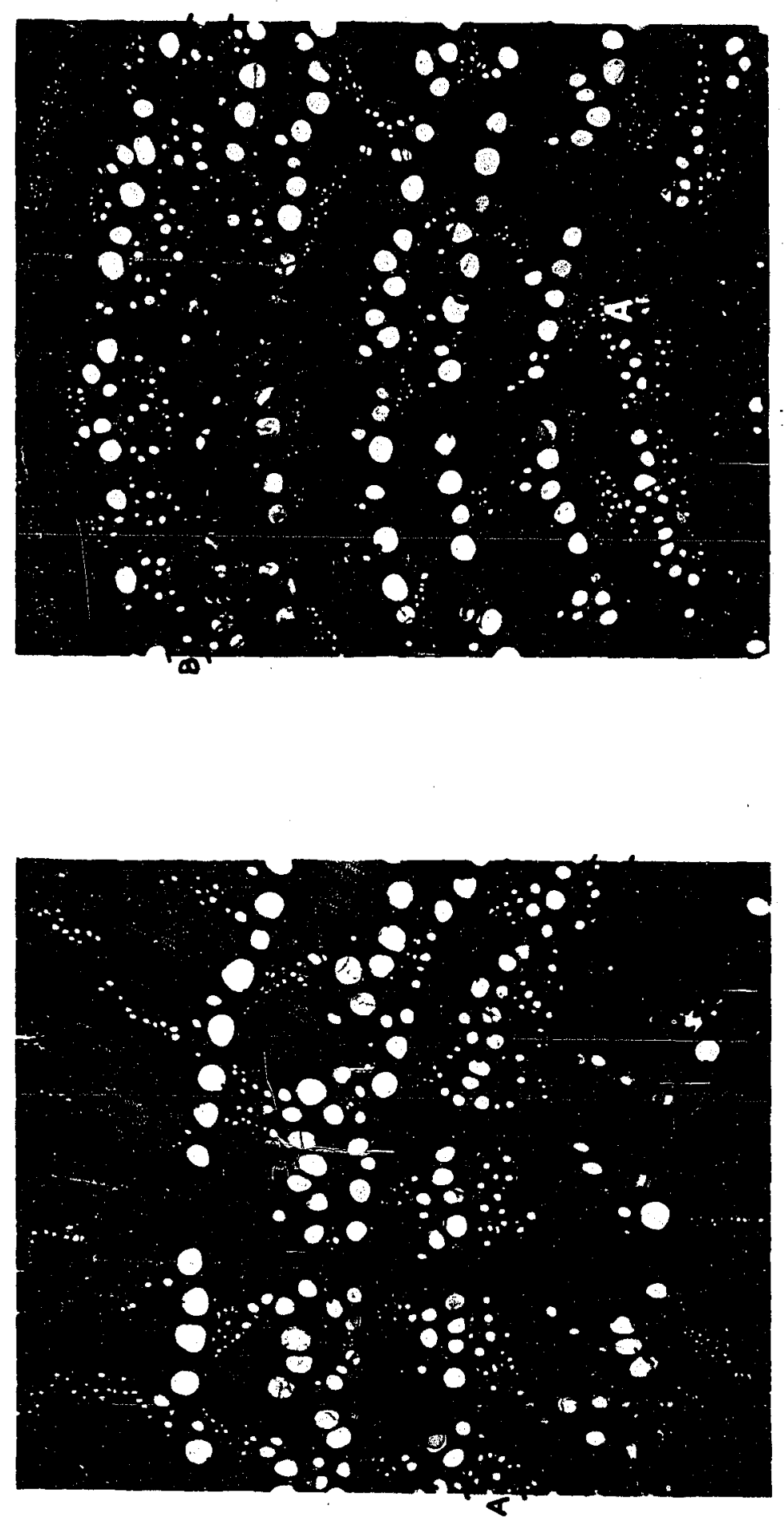
Figure 21. Metaphase observed in cambial zone of bur oak branch 8X (no treatment), collected 22 April 1961 from Pilot Knob State Park, Hancock County, Iowa $(970 x)$

Figure 22. Early anaphase observed in cambial zone of bur oak branch 42F (drill-check), collected 15 october 1960 from Pilot Knob State Park, Hancock County, Iowa $(970 x)$ 

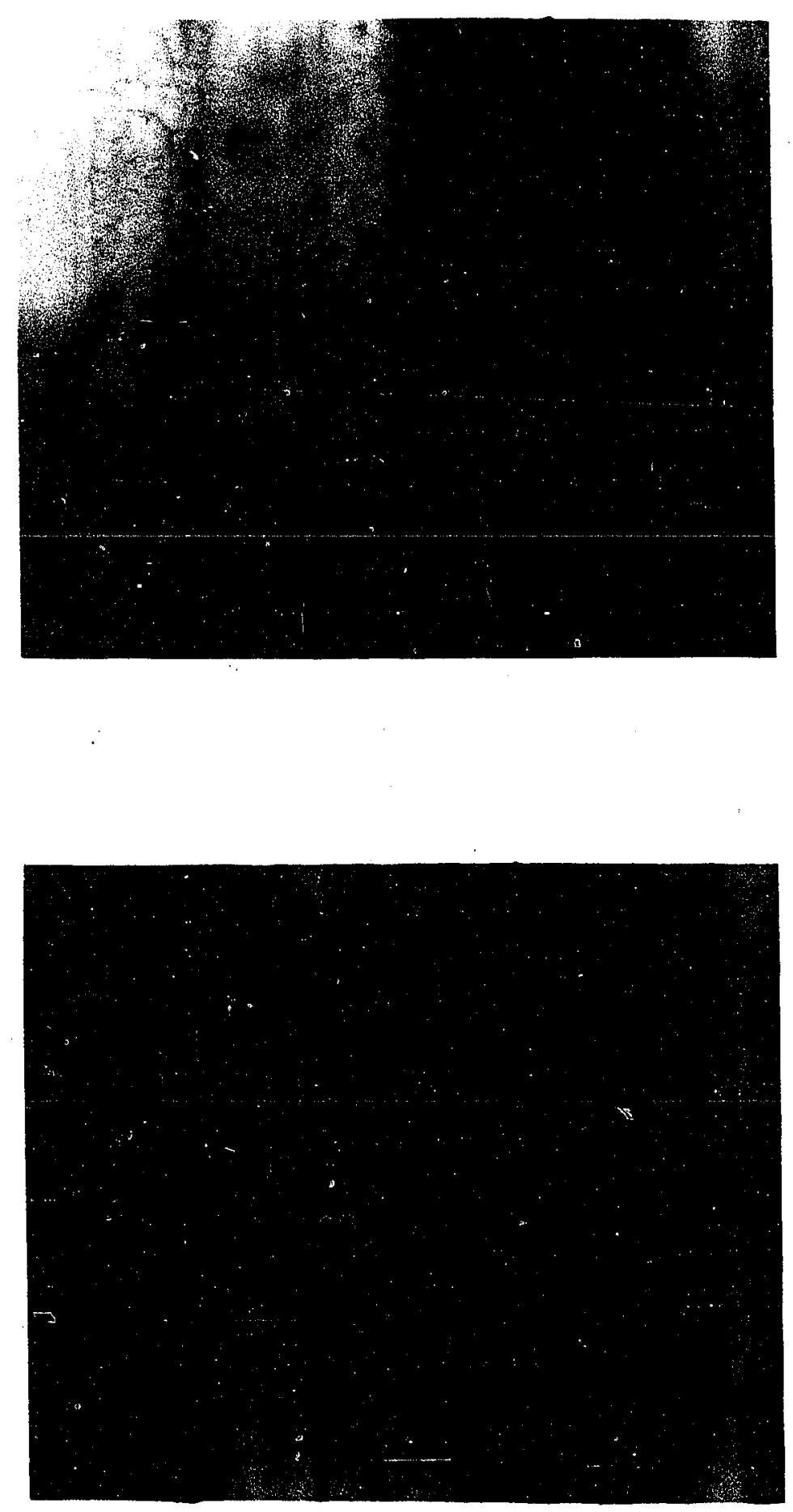
of year. Mitotic divisions were observed more frequently in material collected during the latter part of May and June than in material collected before or after that period. The frequency of periclinal divisions appeared to be greatest during late May and June.

Cambial divisions were observed in August in two branches one and two weeks after they had been defoliated as a result of oak wilt (Figures 23 and 24).

\section{Healing of Drill Wounds}

Tangential and transverse sections which included wounds made by drilling were studied. The reactions induced by wounds varied considerably in extent and rate. However, the general reaction to drilling appeared to be uniform. A detailed time schedule of sequence of events after wounding was difficult to assemble. Most of the material observed in this study was collected at two-week intervals.

Shortly after drilling, tylosis formation was initiated in vessels adjacent to and broken by the wound. Tissue immediately around the wound became discolored and parenchyma within the discolored zone died. The discolored zone in the xylem was extended more along the axis of the branch than transverse to $i t$. In the phloem the zone of injured or killed cells was of less extent along the branch axis than the discolored zone in the xylem. Phloem cells surrounding the 
Figure 23. Metaphase observed in cambial zone of branch 43C, inoculated $7 \mathrm{July} 1960$, severely wilted 28 July 1960, defoliated 5 August 1960, collected 11 August 1960 from Pilot Knob State Park, Hancock County, Iowa (970x)

Figure 24. Telaphase observed in same cambial section as metaphase illustrated above (970x) 

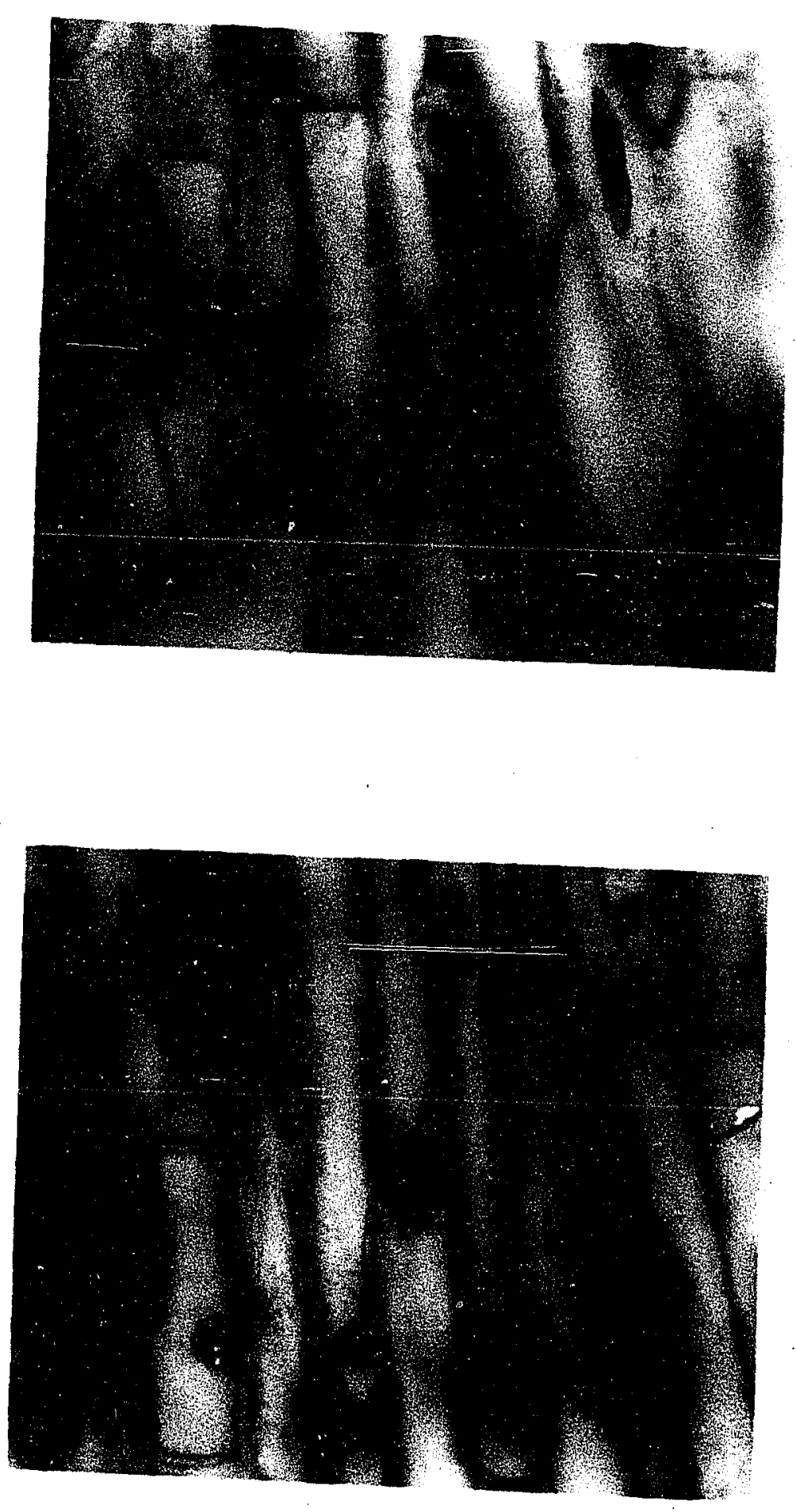
tissue wounded or killed by drilling became meristematic and formed a cylinder of wound periderm continuous at either end with the cambium and newest periderm, respectively (Figures 32 and 34).

Concurrent with the above processes, callous tissue originating at the juncture of the cambium and wound periderm proliferated into the drill hole (Figures 25 through 30), forming a peg-like structure. Staining with either iron hematoxylin, or safranin and hemalum revealed zonation of tissue in the peg (Figure 26) resembling a series of concentric cylinders. Outermost was a shell of crushed cells enclosing a zone of large, thin-walled dead cells. The innermost cylinder consisted of living parenchyma. Those parenchyma cells toward the center of the inner cylinder and those at the base of the peg were lignified and thick walled; those along the periphery of the innerm st zone appeared nonlignified and presumably were the youngest cells in the peg. staining with sudan IV revealed the walls of the layer of dead cells contiguous with the non-lignified living cells were suberized (Scott 1948). Therefore, the wound was isolated from unaffected tissue by the heavily gummosed zone of dead cells around the hole itself and by the suberized layer enclosing living portions of the peg.

Callous cambium was formed across the wound tissue much in the same manner as interfascicular cambium, thereby 
Figure 25. Longitudinal section of hole in drilled in bur oak branch; origin of callus at juncture of wound periderm (A) and cambium (B); wound periderm contiruous around the proliferated callous tissue; band of phloem fibers (C) contained in xylem, the result of previous injury $(36 \mathrm{x})$
Figure 26. Fully developed callous peg in hole drilled in bur oak branch showing zonation; (1) outer crust of crushed phellem like cells and probably also fragments of phloem tissue killed by drilling, (2) zone thin-walled, cuboidal phellem-like cells similar to those in phellem of wound periderm (A) - innermost layer of cells of zone 2 suberized, (3) non-lignified parenchyma cells probably including cambiform layer, (4) thickwalled lignified parenchyma, maximum lignification and gummosis occurred at the base of peg; note production of callous by wound periderm in hole through phloem (36x) 

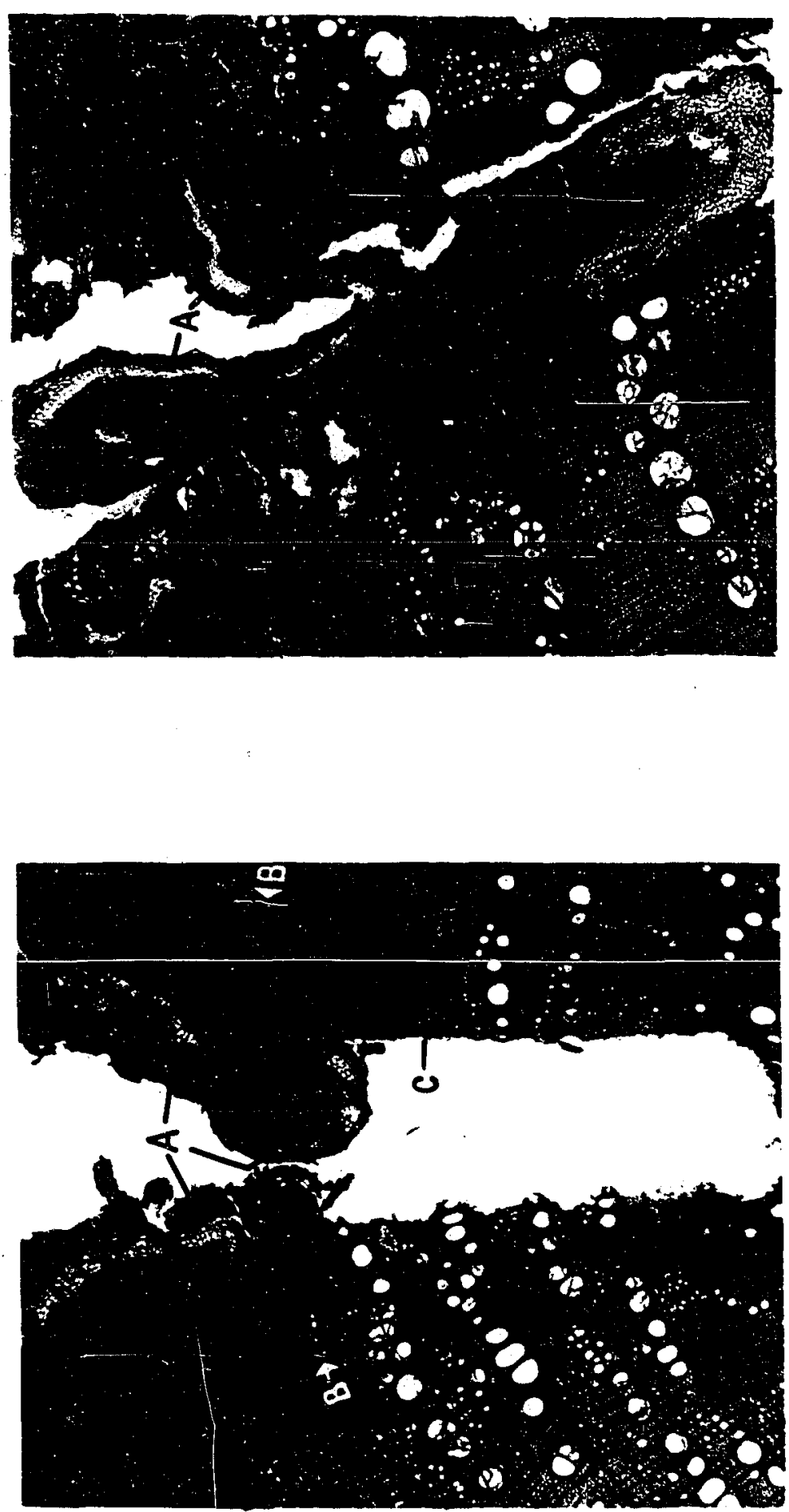
Figure 27. Early stage of healing of holes drilled in bur oak; callous tissue arising from cambium and reactivated phloem parenchyma; tissue at right (A) is xylem (60x)
Figure 28. Callus from both sides of wound filling cavity; sections of callous tissue in the right side of hole originated above plane of section $(60 x)$ 

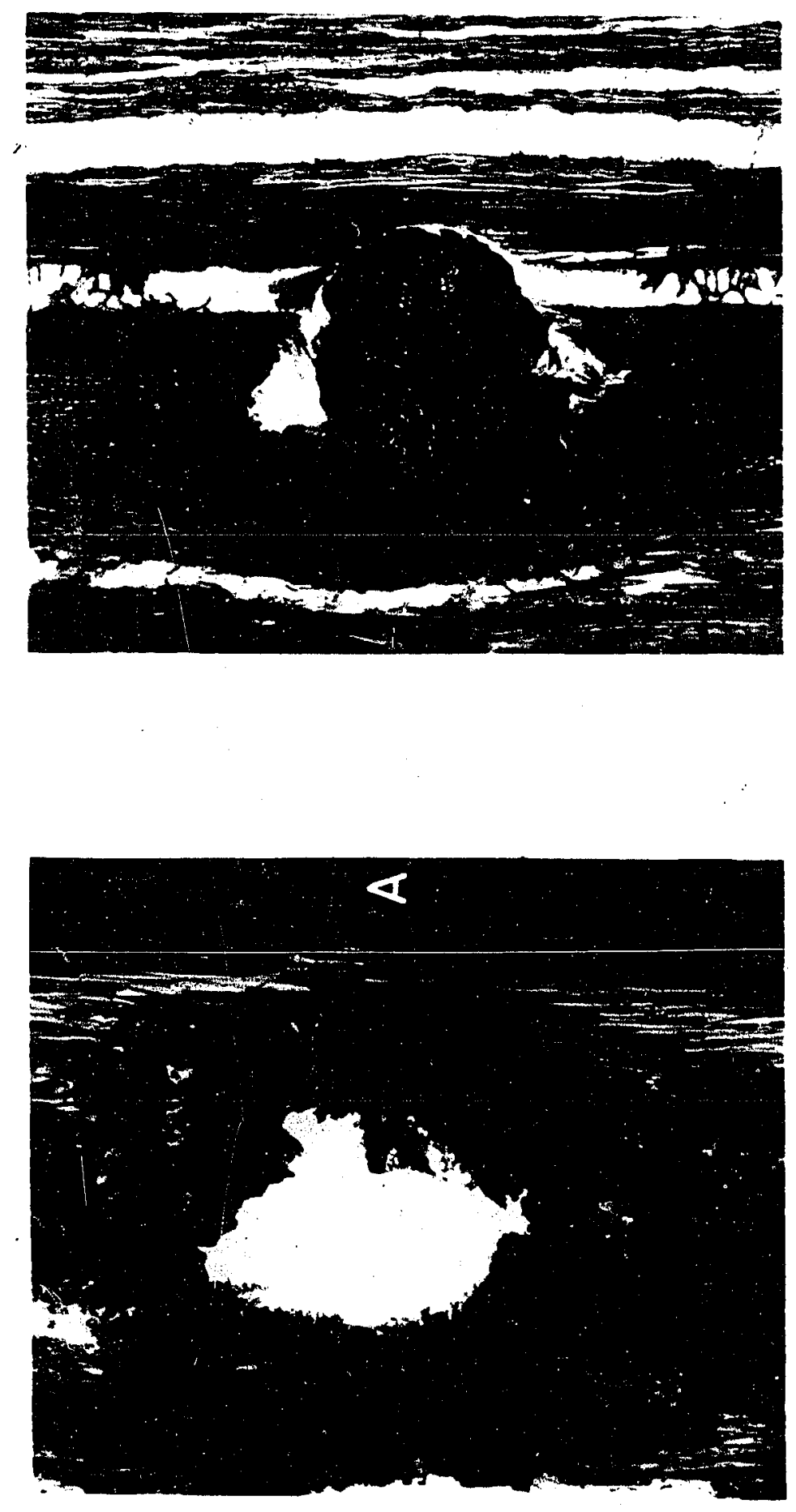
Figure 29. Cross section of callous peg in hole drilled in bur oak branch showing part of peg

(A) arising from proliferation of cells of multiseriate ray (B) cut by drill; other part of the peg. (C) originated above plane of section; it appeared ray cells had been derived from vascular cambium shortly before wounding $(60 x)$
Figure 30. Cross section of callous peg, probably including only zones 1 and 2 as described in Figure 26 $(60 x)$ 

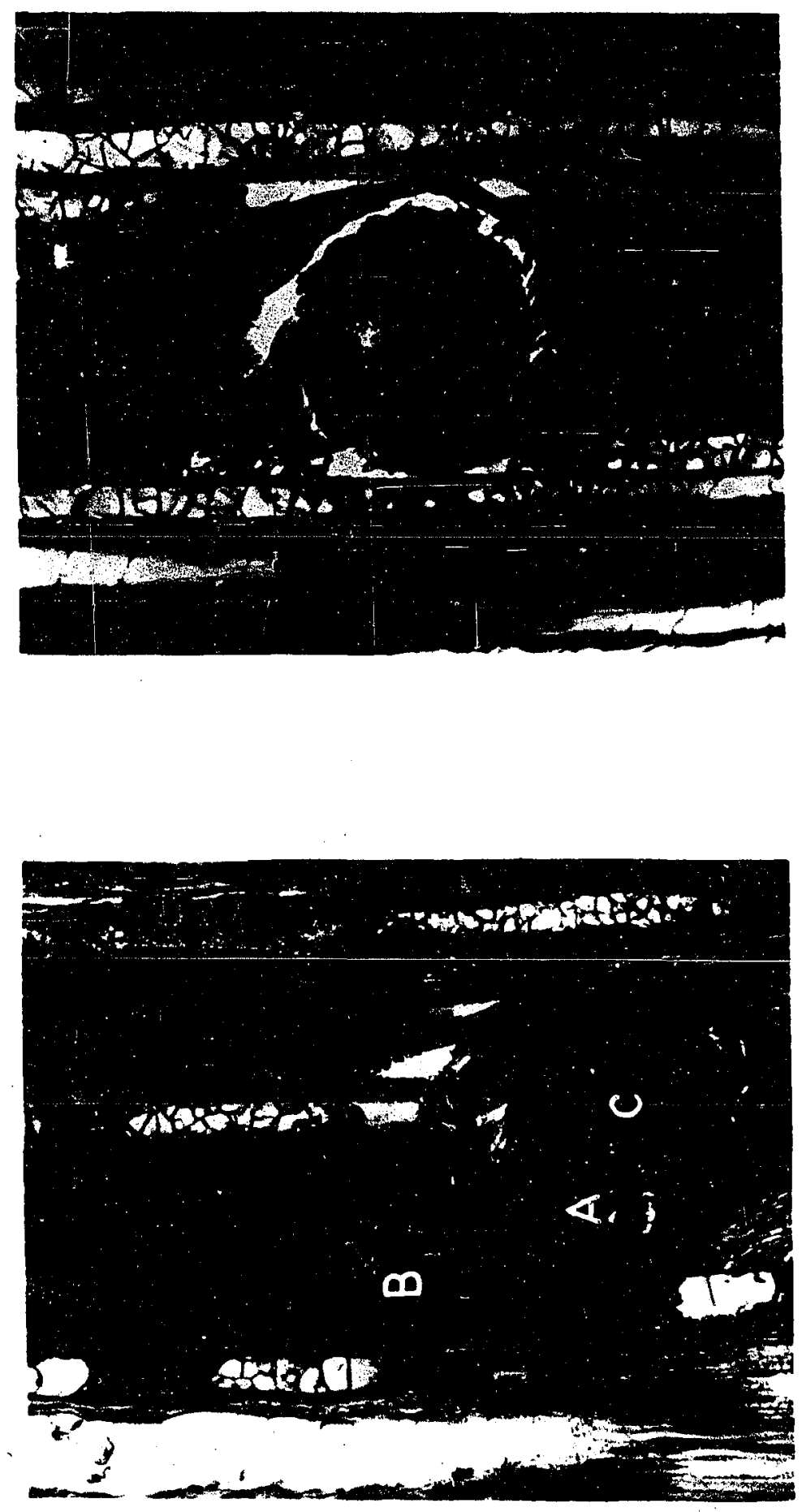
Figure 31. Tissue produced over hole drilled in bur oak branch by newly formed cambium in callous tissue, note radial alignment of cells, compare with Figure 27 (60x)
Figure 32. Tissue produced after that shown above, radial cell alignment no longer evident, although tissue not typical of normal wood $(60 x)$ 

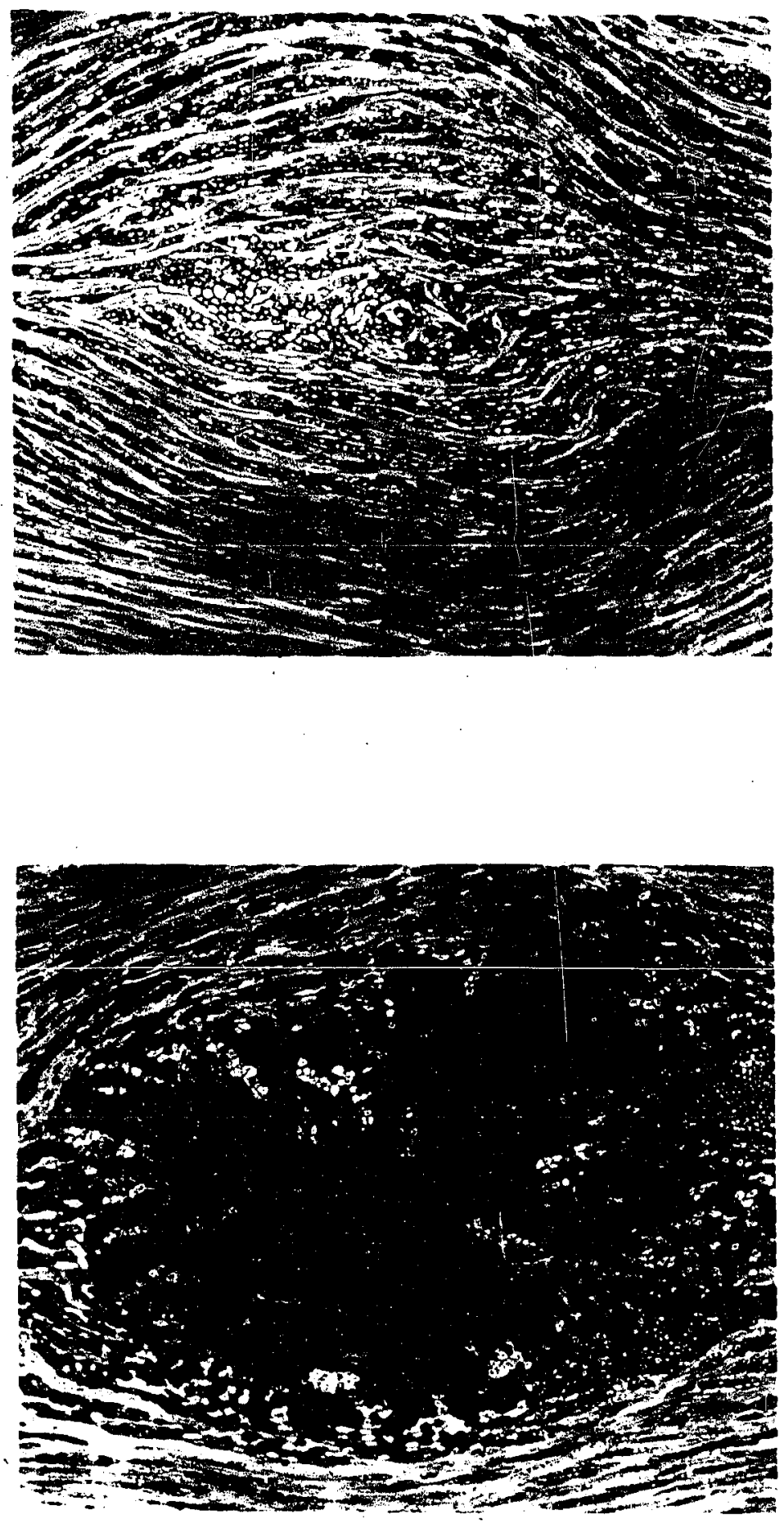
restoring the continuity of the cambium (Figure 34). Ultimately normal xylem was produced to the exterior of the wound tissue, thereby restoring the continuity of subsequently produced annual increments of xylem (Figures 31 and 32).

Frequently callous tissue was proliferated outward through the hole in the bark as well as into the xylem (Figures 26 and 34 ).

One of the holes drilled into branch $17 \mathrm{~J}$ cut into a multiseriate ray. The ray cells, as well as the callus arising from the cambium and wound periderm, proliferated into the cavity (Figure 31 ). Branch $17 \mathrm{~J}$ was collected eight weeks after wounding. By that time continuity of the cambium had been restored and the wound almost completely healed (Figures 31 and 32 ).

An earlier statement indicated that healing of drilled wounds varied considerably in extent and rate. Most striking were comparisons between holes drilled on 1 April 1961 and 1 June 1961. Two weeks after I April inoculations the only observable response was the occurrence of a few immature tyloses immediately above the wounds. It was 13 May before any of the wounds made on 1 April were observed to be healed. In contrast, one drill wound made on 1 June was completely closed and nearly filled with a callous peg two weeks later.

The extent of tylosis development and discoloration along the branch axis in the xylem was greater in branches wounded 
between the middle of May and the end of June than in branches wounded before or after that period.

Apparently all variations in wound healing were not attributable to the time of wounding. Differences were noted between branches wounded on the same day. The best example of extreme variation in healing of identical wounds was observed in branch 13G, inoculated on 1 April 1961 and collected on I June 1961. Both inoculation sites were in the same cutting plane (Figure 33 ). One wound was completely closed and contained a well developed callous peg (Figure 34). The cambium was continuous through the callus and callous tissue had proliferated outward through the hole in the phloem. The other wound was not closed (Figure 35). The wound periderm was well developed and the discolored zone around the hole was evident, but callus had hardly begun to proliferate into the cavity of the wound.

\section{Other Wound Phenomena}

Reactions to other pathological and mechanical injuries were observed during the course of this study. Three of these injuries resulted in reactivation of otherwise non-dividing parenchyma in various tissues.

In one instance reactivation and.stratification of pith parenchyma was induced by disruption of the tissue by an unknown agent (Figures 36 and 37 ). 
Figure 33. Section through both inoculation sites of bur oak branch 13G, inoculated I April 1961, collected 1 June 1961; extreme variation in healing rate, see Figures 34 and 35 greater magnification of wounds $(11 x)$ 


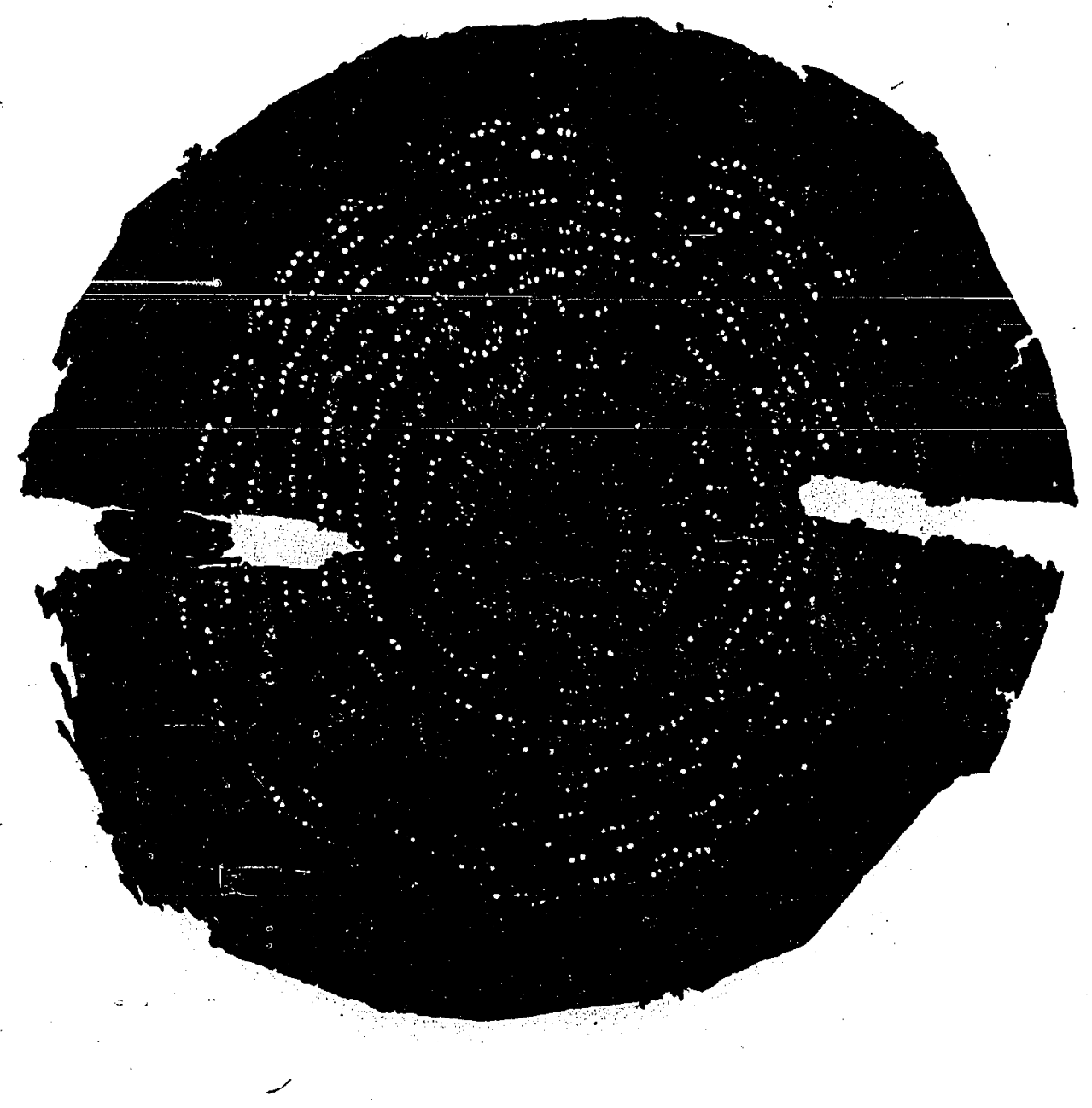


Figure 34. Close-up of completely closed hole drilled in bur oak branch 13G, inoculated 1 April 1961, collected 1 June 1961; continuity of cambium restored by formation of callous cambium (A) (36x)

Figure 35. Close-up of open hole in branch 13G; prominent wound periderm (B) and xylary discoloration around wound, but the lack of callus and normal growth, cambium (A); compare with Figure 34 $(36 \mathrm{x})$ 

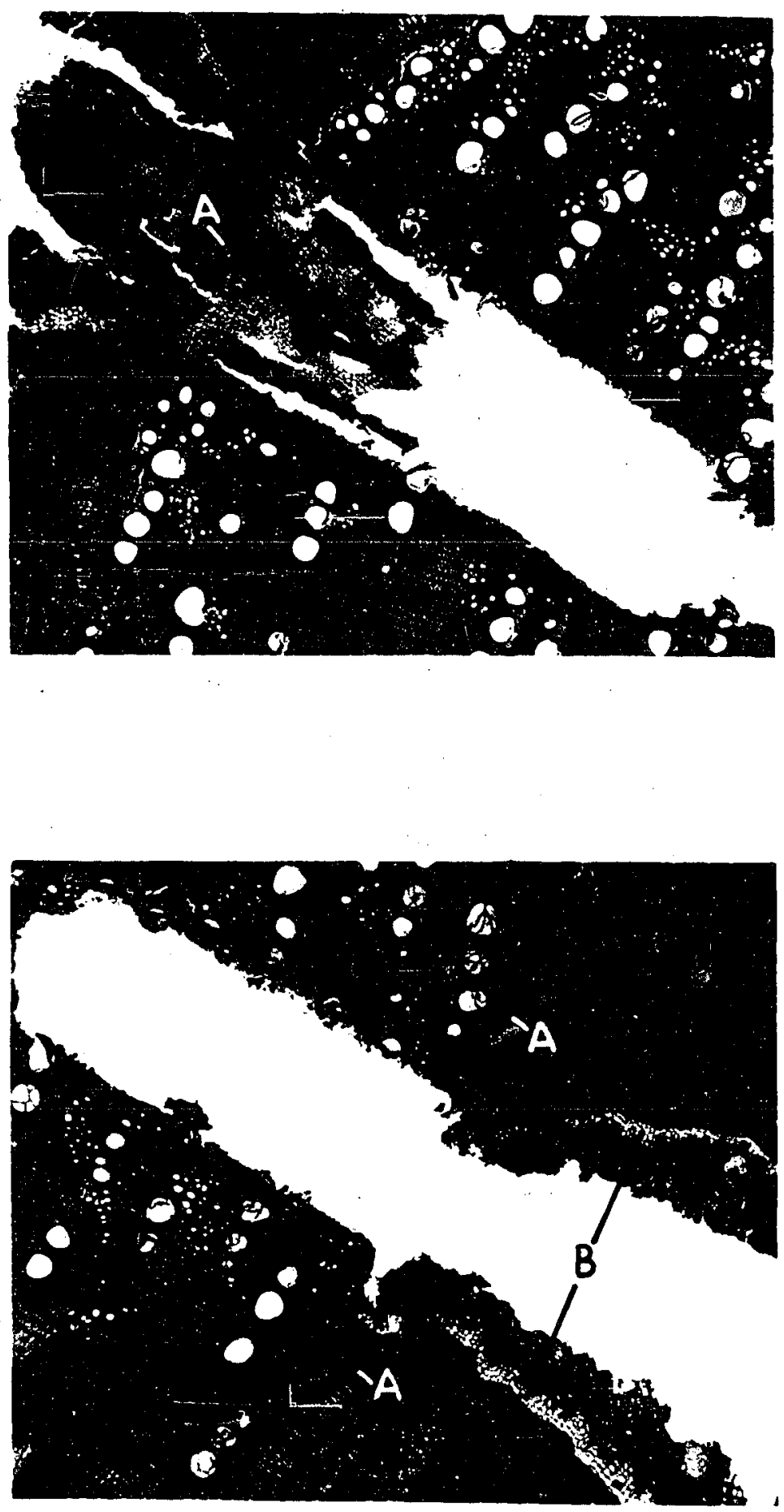
Figure 36. Radial section of bur oak branch, cambiform zone in pith; collected in Pilot Knob State Park, Hancock County, Iowa $(36 x)$

Figure 37. Close-up of cambiform zone (A) in pith (95x) 

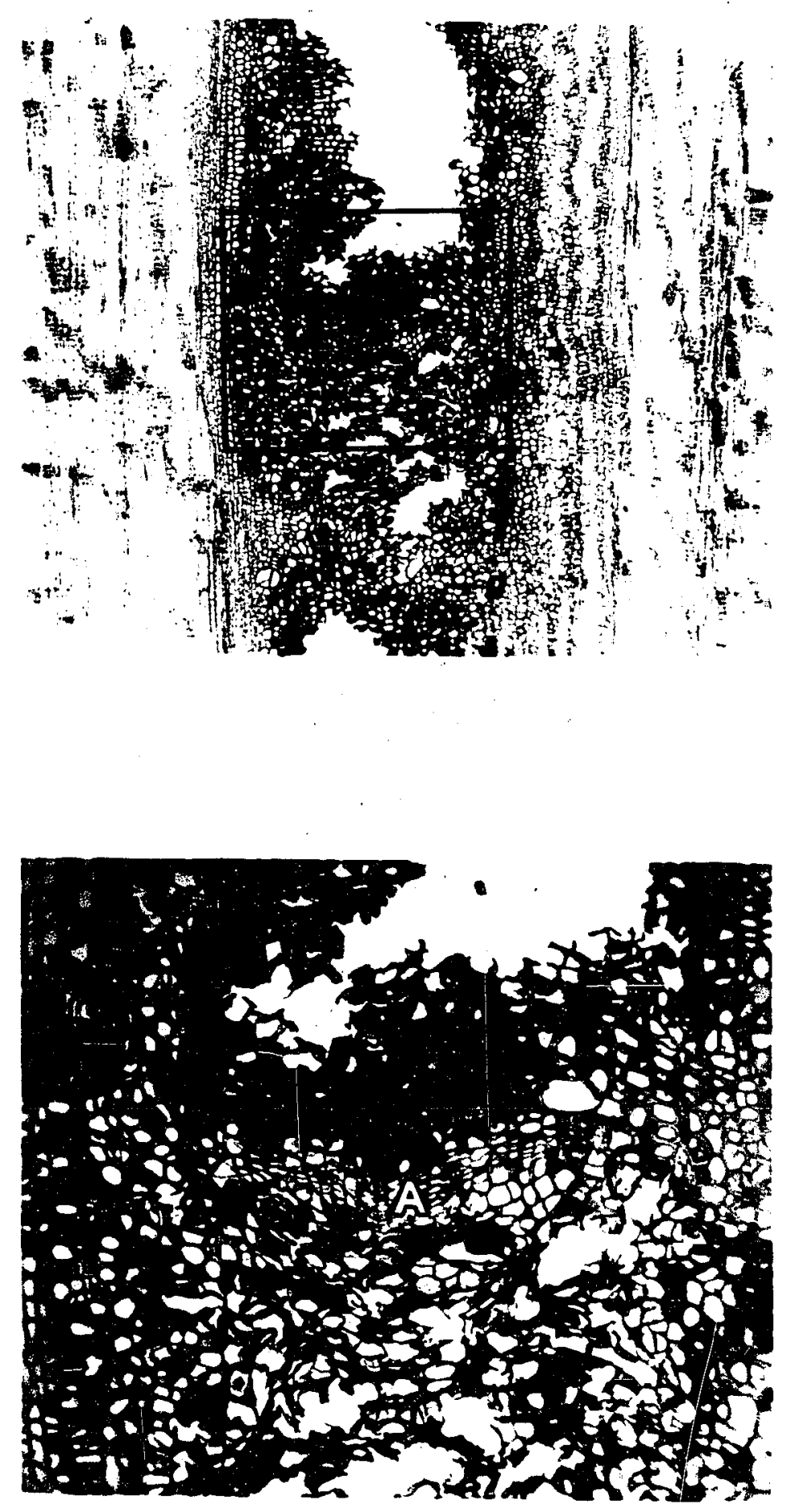
In sections from two branches vessels crushed by enlarged xylem parenchyma were observed (Figure 38 ). Whatever the cause, the reaction was effected shortly after the cells involved were derived. The enlarging parenchyma were not lignified; however it was difficult to determine whether the crushed vessels were fully or partially lignified during collapse. Many of the parenchyma cells had enlarged by five diameters relative to unaffected xylem parenchyma in adjacent tissue. Of nine sections mounted, this phenomenon was observed in only three, indicating a very localized reaction.

A number of times small patches of xylem were observed in secondary phloem tissue. In one instance the cause was fairly certain. At the time of culturing, it was noted that sample 10J-2 contained numerous bark-beetle galleries. In microtome sections of the same sample, portions of galleries were evident. In localized areas of phloem in the vicinity of galleries reactivation of phloem parenchyma occurred and definite cambiform layers were formed. The small isolated patches of xylary cells were-derived from the cambiform cells (Figures 39 and 40). Similar formations have been induced in chestnut (Rumbold 1920).

The final phenomenon to be discussed was encountered quite commonly. Patches of dead phloem tissue were observed entirely contained in xylary tissue (Figure 43). Some of the 
Figure 38. Collapse of vessel walls (A) by hypertrophied ray and xylary parenchyma in bur oak branch collected in Pilot Knob state Park, Hancock County, Iowa 


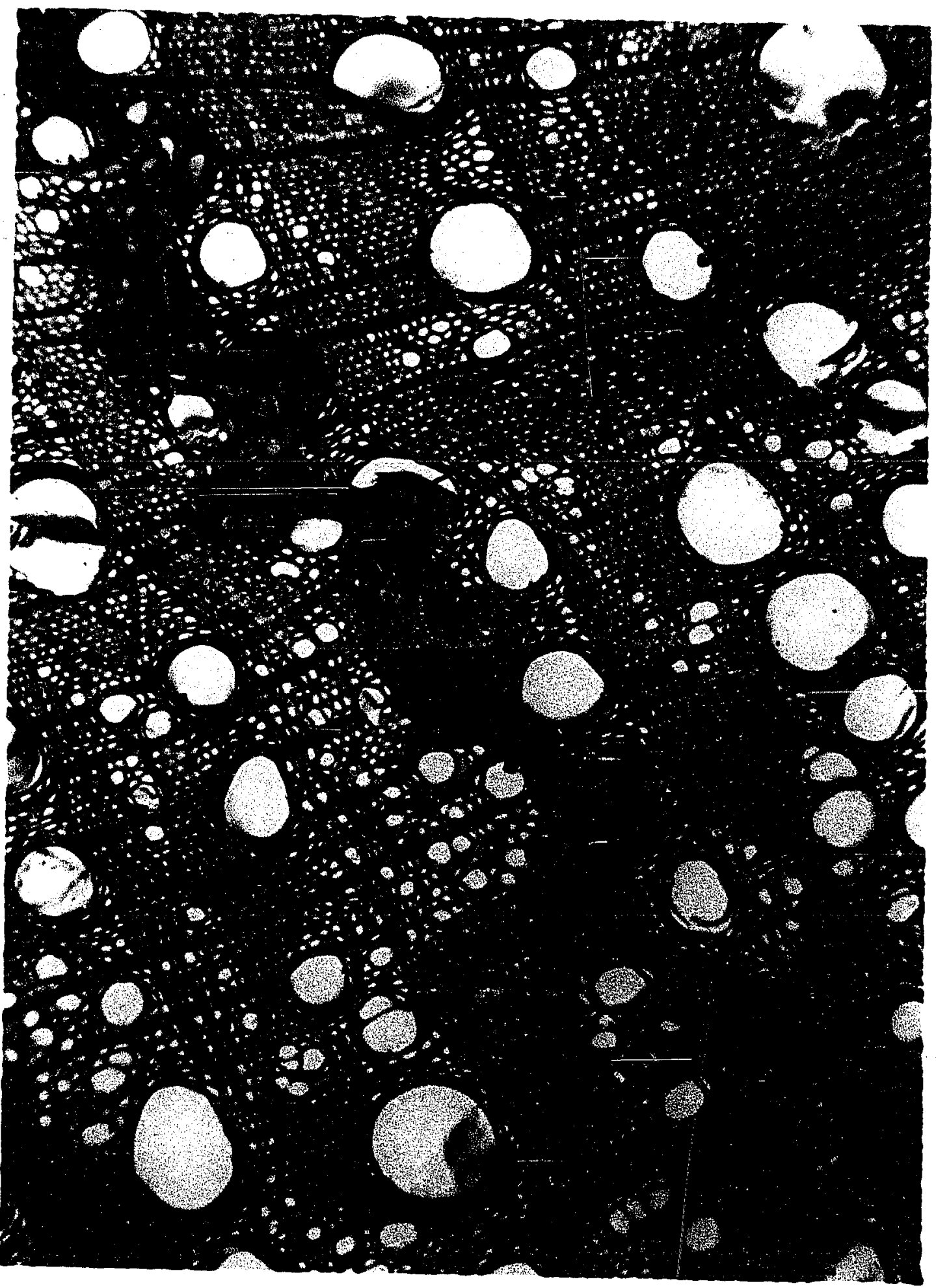


Figure 39. Bur oak branch 10J, inoculated 1 June 1961, collected 24 August 1961; local reactivation of phloem parenchyma near bark-beetle galleries (A); patches of xylem (B) and cambiform layers (C) from which xylem was derived; tylosed vessels and double band (D) wilt-induced (60x)

Figure 40. Another part of same section as above, cut into beetle gallery (A) and local xylem production

(B) by cambiform layer (C) in phloem $(60 x)$ 

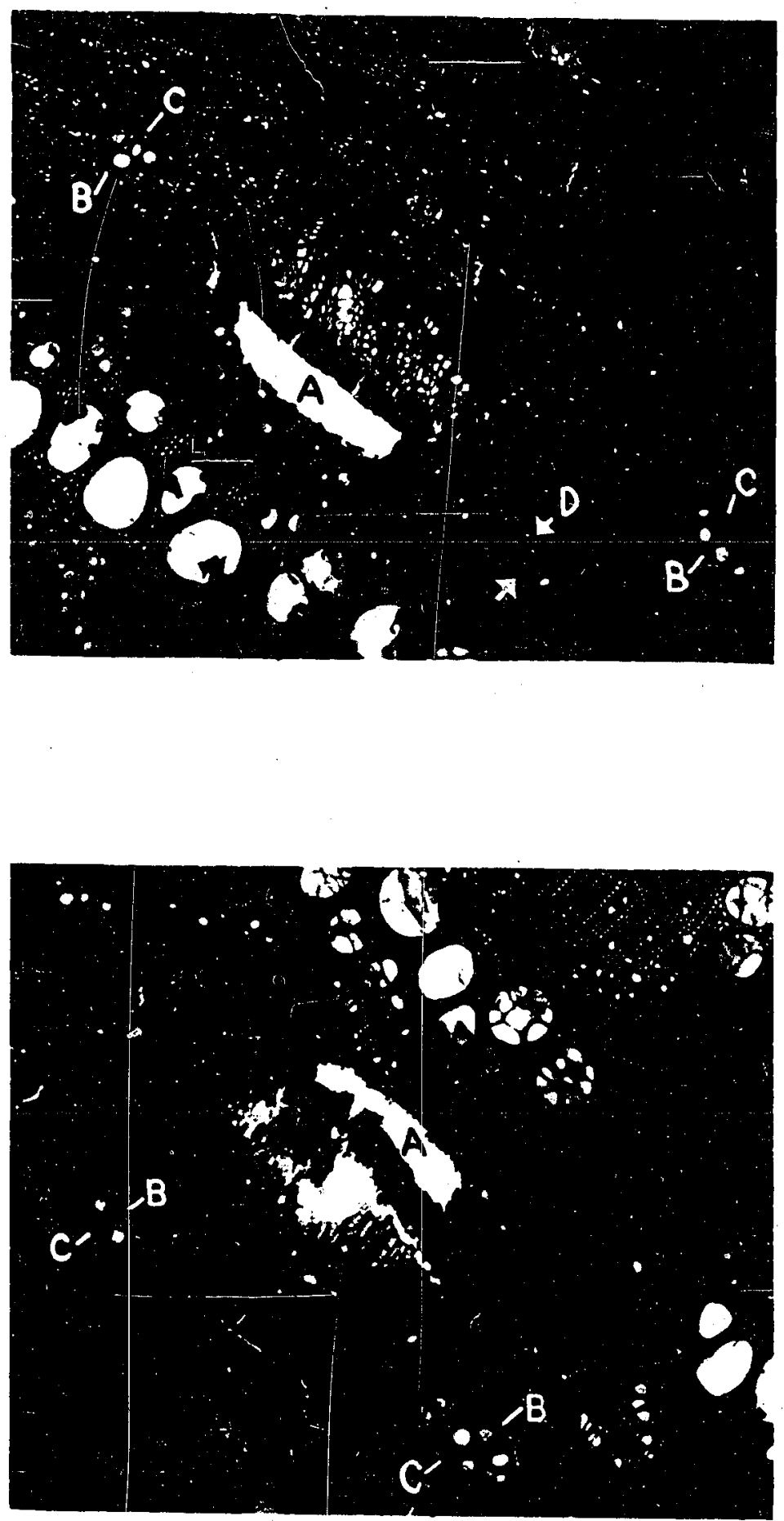
patches extended two to three centimeters longitudinally. Others were only a few millimeters long. In those cases observed, the cause of death of the enclosed patches of phloem appeared to have been internal and originating in adjacent xylem. Invariably the xylem immediately bordering the inner side of the dead phloem was heavily gummosed and tylosed; however, the amount of dead phloem enclosed in the subsequently produced xylem varied from an area containing several bands of phloem fibers to almost none.

The phloem parenchyma nearest the junctures of dead phloem and living cambium probably became reactivated first. The zone of reactivated phloem parenchyma gradually extended around the dead phloem until a continuous cambiform layer was formed (Figure 41). This sequence of events would be analogous with the formations of interfascicular cambium and callous cambium.

Usually the first cells produced by the newly formed cambium enlarged little, if at all, and became heavily gummosed and suberized. Gummosis diminished and soon ceased in subsequently produced wound tissue. At maturity the nongummosed wound cells were typical sclerotized parenchyma. Ultimately the new segment of cambium gave rise to the normal components of bur oak xylem. This process of containment and recovery may be completed within a growing season or it may require several growing seasons, probably depending upon the 
Figure 41. Early stage of isolation of dead phloem (A) in bur oak branch by reactivation of phloem parenchyma (B) surrounding dead tissue and continuous with the cambium; a few cork cells (C) are evident; collected in Pilot Knob State Park, Hancock County, Iowa

Figure 42. Dead patch of phloem (A) isolated from other tissue by zone of suberized cells (C) produced by -wound cambium (B) (36x) 

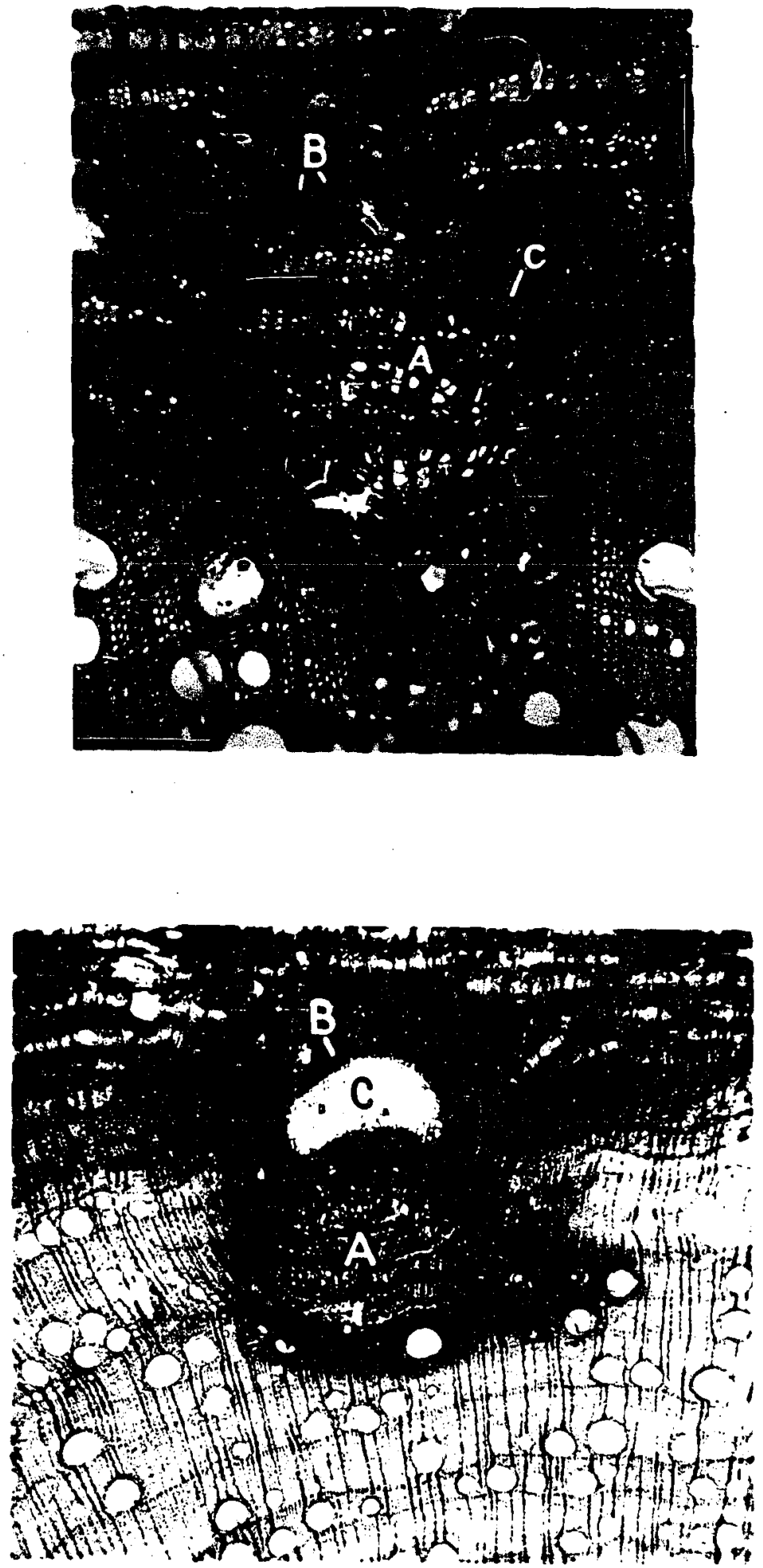
Figure 43. Isolated dead phloem (A) surrounded by xylem (B) produced by reactivated phloem (C) functioning as vascular cambium, in bur oak branch collected in Pilot Knob State Park, Hancock County, Iowa

Figure 44. Close-up of dead phloem pictured above; killed phloem (A), wound phellem (B) and gummosed xylary parenchyma (C); note similarities among normal periderm (Figure 33), drill-wound periderm (Figure 35) and suberized tissue shown here (95x) 

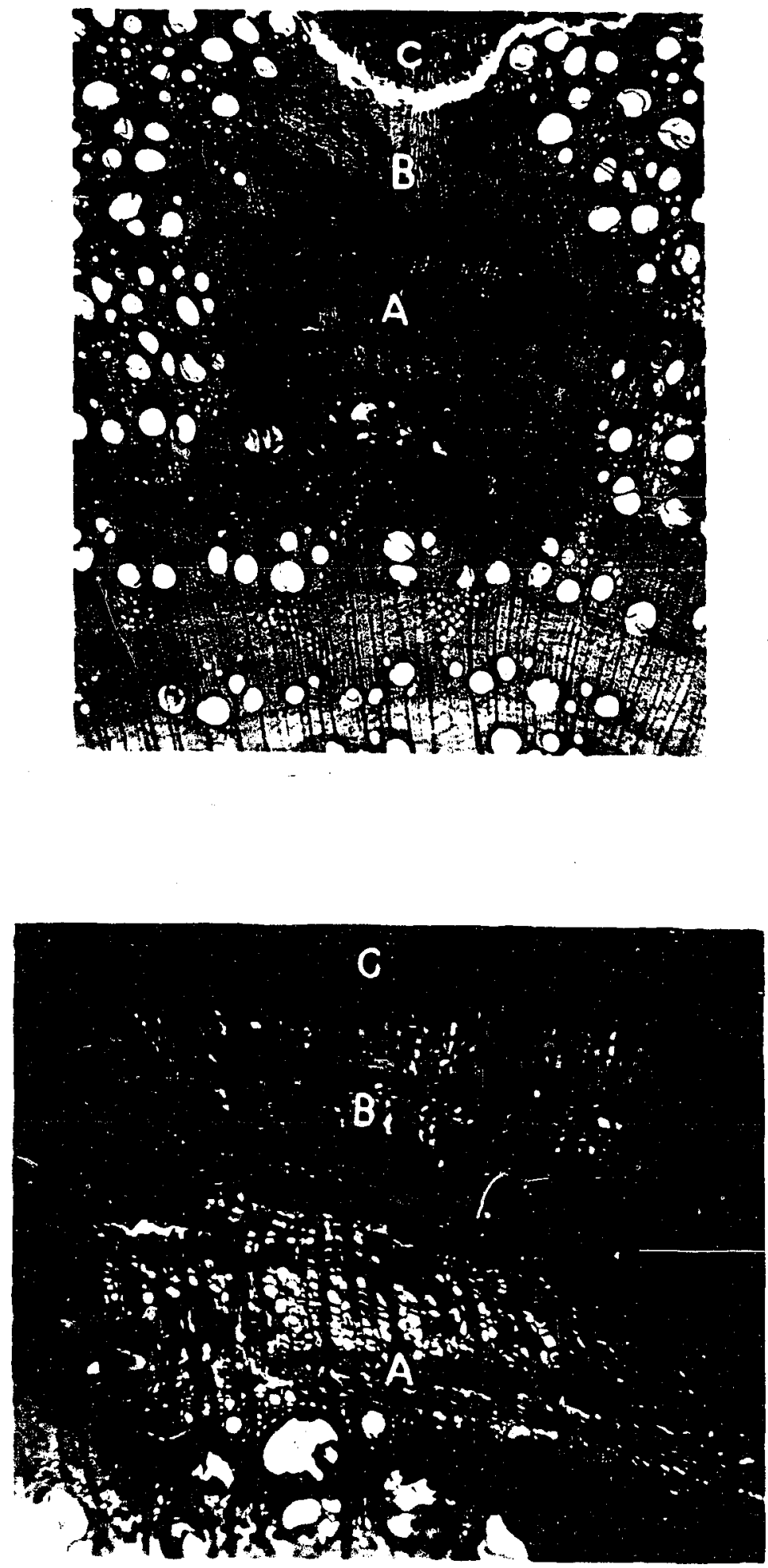
vigor of the tree and the severity of the wound.

In more severe cases (Figure 42), additional cork tissue was produced between the first suberized zone and the wound parenchyma. The first layers of additional tissue consisted of larger, cuboidal, suberized cells, followed by several layers of more typical narrow cork cells. This cork tissue, typical periderm and periderm formed around drill wounds appeared very similar in constitution (compare Figures 42 and 35 ).

After cork tissue, typical wound tissue was produced and ultimately typical xylary components were differentiated (Figure 43). In almost all instances observed, the rays became discernible in the wound tissue adjacent to the cork layer. 


\section{DISCUSSION}

The study presented herein was designed primarily to investigate the development of oak-wilt-induced xylem formation and the effects of the time of infection and other factors on the development of wilt-induced tissue. Less than 15 percent of the branches inoculated by the techniques described had become diseased by the time of collection.

Undoubtedly, part of the apparent failure to infect can be attributed to the sampling schedule. Approximately 75 percent of the diseased branches developed foliar symptoms four or more weeks after inoculation. By the end of the fourth week after inoculation half of the initial population of inoculated branches had been eliminated by periodic sampling. Presumably other branches would have developed foliar symptoms of oak wilt had they not been eliminated beforehand.

Many other fungi and bacteria were isolated from bur oak branches, both inoculated and uninoculated. The presence of a diverse microflora in xylem of white oaks has been reported (Wood and Peterson 1959). It is probable that such contaminants masked in culture the presence of $\underline{c}$. fagacearum in infected bur oak branches. Possibly the activities of certain microorganisms in the xylem rendered branches unfavorable for the establishment of $\underline{C}$. fagacearum. The activities of the internal microflora of bur oaks are unknown and little is 
known about competition in vivo between $\underline{\mathrm{c}}$. fagacearum and other microorganisms.

Although the oak wilt organism did not appear to compete well with other organisms on an agar medium, it may be more competitive in the environment of the branch. When branches $38 \mathrm{~B}$ and $51 \mathrm{~B}$ were cultured by placing discs on the medium, only contaminants eimerged from the wood. When the same two branches were cultured by placing small chips from prominently

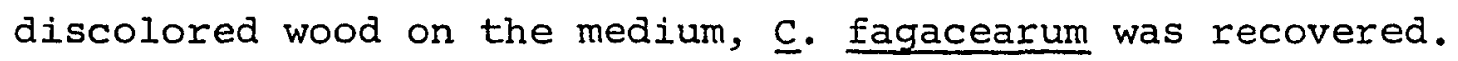
Possibly the oak wilt organism was established in certain sectors of the branch and other microflora in other sectors. When discs of wood including all sectors were cultured, the contaminants emerged first, grew more rapidly, and mechanically or chemically inhibited the growth of $\underline{C}$. fagacearum.

Incidence of infection varied with time of inoculation. Disregarding the year of inoculation, most infections resulted from inoculations performed between 13 May and 23 June. The sporiferous mat-and-pad structures of $\underline{C}$. fagacearum have been found to be abundant at Pilot Knob state Park during late April, May and early June (Engelhard 1955). Appearance of foliar symptoms on artificially inoculated branches and in naturally inoculated trees in Pilot Knob State Park coincided very closely. The period of maximum inoculation success coincided closely with maximum mitotic and other metabolic 
activity in the host, as indicated by the increased frequency of observed mitoses and the depletion of starch reserves in the branches. It was noted that reactions such as production of tyloses and callous tissue induced by drilling generally were most rapid and extensive during May and June, even when holes were drilled in April.

The distribution of isolates of $\mathrm{C}$. fagacearum in infected branches of the same tree indicated preferential susceptibility of certain trees to one or the other isolate. The chances of the distribution of isolates occurring independently of the trees involved were very slight (Cochran 1954; pp. 425-427), assuming each infection was an independent event and each isolate had an equal opportunity to become established in each branch. It is unlikely that any inconsistencies in inoculating techniques should favor consistently one or the other isolate in all branches of a given tree. on nearly all trees inoculated branches developed foliar symptoms before other branches. If the infections of all the inoculated branches had resulted from only one or two successful inoculations, then presumably uninoculated branches interspersed among the inoculated branches should have had as much chance of becoming infected by $c$. fagacearum as branches in which inoculations were unsuccessful. Therefore it was indicated that each infection of inoculated branches had been an independent event in most, if not all instances; and that 
certain trees were preferentially susceptible to one or the other isolate of $\underline{C}$. fagacearum.

Since the genetic backgrounds and physiological conditions of trees and of isolates used during this study were unknown, little can be discussed concerning why specific trees appeared more susceptible to infection by one or the other isolate; or in terms of the pathogen, why one or the other isolate was better adapted to infect specific trees.

In view of the results obtained from inoculations made on 23 June 1960, and on 13 May and 1 June 1961, the low incidence of disease obtained from inoculations on 9 June 1960 were difficult to reconcile. One would expect that bur oaks should have been as susceptible to infection on 9 June as before and after that date. Weather conditions were typical for the season at Pilot knob State Park, namely bright, humid, warm, and slightly windy. The inoculations were performed in the same manner as those performed in subsequent experiments. The most plausible explanation appeared to be that the trees designated for the first series of inoculations were resistant to infection, under the conditions of the experiment. However, since none of the trees inoculated on 9 June 1960 became systemically infected and only three branches developed foliar symptoms of oak wilt, the adequacy of procedures on that date could not be evaluated. The results obtained from inoculations made on 23 June 
1960 and 1 June 1961 indicated certain trees were resistant to infection by either isolate. According to the over-all results, the experimental trees were more susceptible to infection during late May and June than before or after that period. Yet none of the inoculations in some trees was successful, whereas a high proportion of inoculations was successful in others. Again assuming each branch infection was an independent event, the chance occurrence of such a distribution of infected branches among the trees appeared slight.

To determine whether or not the indicated resistence to infection is heritable was not within the scope of this study. Whether or not the apparently resistant trees would have remained disease-free had they been inoculated with heavier conidial suspensions or with inocula from other isolates could not be determined during this study. Oak wilt has been present in Pilot Knob state Park for at least 20 years. In 1950 an estimated 60 percent of the merchantable oak timber in the park was represented. by wilt-killed trees (Hoffman 1951). Since that time the disease has continued to spread and intensify, both naturally and through experimental inoculations.

The effects of the disease were in evidence in all of the areas of the park in which experimental trees were selected for this study. Probably a high proportion of susceptible. 
bur oaks has been eliminated from the population. Consequently, it is probable that the frequency of resistant trees among those selected for this experiment was greater than it would have been a decade or two ago.

Between the extremes of resistance to infection and death resulting from infection were trees that became infected and later apparently recovered. Trees 11 and 15, in addition to being infected in several artificially inoculated branches, sustained systemic infections in their upper crowns in 1960. In 1961, stagheading was observed, but the remaining artificially inoculated branches had recovered from the effects of oak wilt. Double-banding was observed in all recovered branches of all experimental trees, as well as in the main stem of Tree 11. Double-banding was observed also in diseased branches collected during the seasons in which infections occurred, some of the branches ultimately having been killed by oak wilt. Double-band formation was initiated in branches inoculated as early as 22 April in 1961 and as late as 4 August in 1960 .

Double-banding was initiated in two branches before foliar symptoms developed. It was observed in branches from 14 of 18 trees from which infected branches were collected, although double-banding was not observed in all infected branches of the 14 trees. The branches in which double-banding was initiated varied in vigor, as indicated by the 
differences in width of the current increments. However, double-banding was greater in radial extent in vigorous branches infected early in the growing season than in less vigorous branches or branches apparently infected after most of the current increment had been produced. Double-banding was not observed in uninfected branches or in branches sustaining other types of injuries. Therefore this production of atypical vascular tissue was a response to the effects of infection by $\underline{c}$. fagacearum.

The response was manifested during the same growing season in which infection occurred. The ability to respond to infection apparently was widespread in the experimental population of bur oaks. Since similar responses were observed in infected white oaks and in a northern pin oak treated with a systemic fungicide prior to inoculation (Schoeneweiss 1959), the genetic capability to produce wiltinduced tissue may be widespread throughout the genus. The factor preventing the response in members of the red oak group may be the rapidity of the disease cycle and consequent inactivation of cambial initials before double-banding is initiated.

Apparently induction of double-band formation and symptomatic tylosis formation could occur more or less concurrently. However, since production of wilt-induced tissue prior to development of foliar symptoms was observed only 
twice, there is not enough evidence to substantiate a consistent association in time of vascular occlusion and the initiation of double-banding.

When infections occurred in May or June, there was evidence of increased cambial activity during the initial stages of double-band formation. The width of the cambial zone was consistently greater in infected sectors than in uninfected sectors.of the same branch. However, differences in widths of cambial zone in diseased and healthy sectors of branches infected arly in the season were not apparent later in the season, indicating increased cambial activity was a transient response. The increased width of annual rings in branches infected in July and producing double-bands indicated there was increased cambial activity at least during the initiation of double-bands induced later in the season.

Apparently the extent of production of wilt-induced tissue was dependent upon several factors. It is hypothesized that the genetic potential to respond in the manner described was not one of them. Diseased branches inoculated on or after. 7 July 1960.produced-wilt-induced tissue, indicating the amount of wilt-induced tissue produced was dependent upon how late in the growing season double-band formation had been induced. Double-band formation appeared to be more extensive in fast-growing branches, indicating the vigor of the infected branch influenced the extent to which double-banding 
developed. The severity of the disease was indicated as an important factor. Double-banding had been initiated in-several branches before the branches succumbed to the disease. In others, it is hypothesized that the branches were killed before double-band formation was initiated. It was impossible to evaluate the relative effects of the above factors upon the extent of double-band formation and upon each other.

It is possible that double-band formation was a response determined by the nature of the injury, rather than by the agent causing the injury. It has been suggested that the activity of $\underline{C}$. Eagacearum was in some way involved in the response, since double-banding did not result from mechanical wounding (Schoeneweiss 1959). However, in the wound area itself cambium was removed or killed, thereby precluding the production of new cells in the wound proper. The occlusion of water-conducting tissue in the vicinity of the mechanical wound was limited in extent along the axis of the tissue. In contrast to the above conditions, infection by $\underline{C}$. fagacearum effected extensive longitudinal occlusion of vascular elements without concurrent death or inactivation of the cambium in bur oaks.

The location of occlusions may be more critical than the extent of occlusions; this question cannot be resolved on the basis of this study. Considerable lateral movement of solutions in oak xylem has been demonstrated by the use of 
dyes in partially girdled trees (Parmeter et al. 1956; Yelenosky and Fergus 1959). Perhaps the occurrence of vascular occlusions in such locations as the junctures of primary branches and the main stem, or secondary and primary branches is critical in effecting the production of new vascular tissue. In such locations lateral movement of xylary solutions would be limited severely by phÿsical structure of the host.

Seasonal fluctuations in starch accumulation observed during this study were similar to those observed by other workers (Preston and Phillip 1911; Sinnott 1918). Starch was absent in parenchyma cells ultimately killed as a result of oak wilt or of other wounds. Therefore, it was indicated that hydrolysis of starch in tissue infected by $\underline{C}$. fagacearum was independent of the agent causing the wound and was a general reaction to wounding.

Several general histological concepts were illustrated in atypical ways by the other traumatically or pathogenically induced reactions observed during this study.

The evidence of cell divisions in the pith, in recently derived multiseriate rays and in phloem tissue several years old illustrated the principle that all living cells that are not overspecialized are capable of dividing mitotically.

The positional effect upon the differentiation of cambial derivatives was demonstrated by differentiation of xylary components inward from localized cambiform layers which had 
been formed in phloem as the result of bark beetle activity. A similar phenomenon was noted in the phloem of American chestnut trees (Castanea dentata [Marsh] Borkh.) that had been wounded in the process of being injected with chemotherapeutants (Rumbold 1920).

The isolation of killed phloem from unaffected phloem involved the reactivation of phloem parenchyma and the formation of wound periderm on the periphery of the killed area, and continuous with the vascular cambium. In every circumstance observed involving the formation of periderm, the phellem was differentiated between the adversely affected tissue or external environment and the phellogen. The histological similarities of periderms resulting from various causes were noted previously. It appeared that these periderms, regardless of the causal agent, were analogous in form and function.

The containment of dead phloem and associated phellem in xylary tissue involved the redirection of differentiation of cork cambial derivatives from phellem and phelloderm to xylem and phloem.

Wound parenchyma, and subsequently normal xylary elements, were differentiated between the phellem and cambium; phloem elements were differentiated between the cambium and phelloderm. The mechanism by which redirection of differentiation was effected is not known. As the vascular cambium was 
advanced by means of xylem production subsequent to the onset of the pathological condition, the changeover from phellem to xylem differentiation appeared to progress around the corkedover tissue.

It is the belief of the writer that all of the phenomena presented herein indicate the evolution of a highly organized, yet flexible, series of reactions to pathological conditions. Apparently host reactions are more dependent upon the kind and location of affected tissues than upon the causal agent. 
VI. SUMMARY

Histological and cultural studies of 348 bur oak branches inoculated at various intervals during the growing season with two macroscopically distinct isolates of Ceratocystis

fagacearum and 144 uninoculated branches were made in order to investigate concurrently the development of wilt-induced vascular tissue, the effect of oak wilt on accumulation of starch in xylem, and competition in vivo among isolates of the oak wilt organism. Reactions of bur oak to otner pathological conditions were observed in order to obtain a better understanding of wound reaction.

Fifty inoculated branches developed foliar symptoms be-

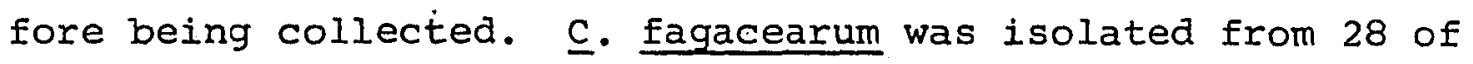
the symptomatic branches and five symptomless branches. The distribution of diseased branches over the entire study indicated 1) certain bur oaks were resistant to infection by either of the isolates used as inocula, and 2) bur oaks were most susceptible to oak wilt during May and June.

Maximum susceptibility coincided closely in time with maximum physiological activity of the host as indicated by increased frequency of observed cell divisions and depletion of starch reserves in xylem. Mechanically induced wound reactions such as formation of tyloses and callous tissue were most extensive and rapid during May and June.

Distribution of isolates among 33 branches of 14 trees 
indicates preferential susceptibility of certain trees to specific isolates may contribute to the apparent competition in vivo among isolates of $\underline{c}$. fagacearum.

Both mechanical wounding and disease resulted in hydrolysis of starch and in deposition of gums in affected xylary, ray, and pith parenchyma. No starch was found in wilt-killed branches, regardless of time of death.

Although only the outer ring was found to be functional in conduction, rings of vessels up to 15 years old in bur oak branches were found free of occlusions, indicating more than cessation of the transpiration stream is required for tylosis formation.

Production of wilt-induced vascular tissue, referred to as double-banding, occurred in bur oaks. Wilt-induced tissue consisted of more numerous, scattered vessels which were slightly larger than typical latewood vessels, more tracheids and parenchyma cells, and fewer fibers than typical latewood. Cambial activity was increased for a short time during the initial stages of double-band formation. Mitotic figures were observed in the cambial zone of healthy trees as early as 22 April 1961 and as late as 15 october 1960, indicating double-band formation did not involve reactivation of the cambium.

It was concluded that the extent of double-band development in bur oaks was influenced by the vigor of the diseased 
part, the severity of disease, and the time during the growing season of induction of the response. The genetic potential for responding to oak wilt by production of new vascular tissue may be widespread throughout the genus Quercus. More rapid colonization and death may preclude initiation of double-banding in diseased trees of the red oak groups. The pathological phenomena studied herein indicate host reactions are more dependent upon the kind and location of affected tissue than upon the causal agent. 
VII. LITERATURE CITED

Barnett, H. L. and F. F. Jewell. 1954. Recovery of isolates of Endoconidiophora fagacearum from oak trees following mixed culture inoculations. Plant Dis. Rptr. 38:359-361.

and J. M. Staley. 1953. Isolation of compatibility types of Endoconidiophora fagacearum from oak trees naturally and artificially inoculated. Phytopathology $\underline{43}: 341-343$.

Beckman, C. H., J. E. Kuntz, A. J. Rikex and J. G. Berbee. 1953. Host responses associated with the development of oak wilt. Phytopathology $43: 440-454$.

Boyce, J. S., Jr. 1957. Oak wilt spread and damage in the southern Appalachians. J. Forestry 55:499-505.

- 1961. Symptoms in relation to infection pattern in white oak. Plant Dis. Rptr. 45:386-387.

and K. H. Garren. 1953. Compatibility types of the oak wilt fungus in 23 Appalachian trees. Phytopathology $43: 644-645$.

Chattaway, Margaret M. 1949. The development of tyloses and secretion of gums in heartwood formation. Austral. J. Sci. Res. Ser. B, 2:224-240.

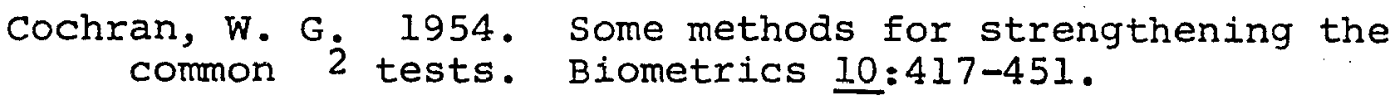

Craighead, F. C., C. L. Morris and J. C. Nelson. 1953. A preliminary note on the susceptibility of wounded oaks to natural infection by the oak wilt fungus. Plant Dis. Rptr. $37=483-484$.

Dorsey, C. K., F. F. Jewell, J. G. Leach and R. P. True. 1953. Experimental transmission of oak wilt by four species of Nitidulidae. Plant Dis. Rptr. 37:419-420.

Dorsey, C. K. and J. G. Leach. 1956. The bionomics of certain insects associated with oak wilt with particular reference to the Nitidulidae. J. Econ. Entomol. 49: $219-230$. 
Engelhard, A. W. 1955. Host-parasite relationships of Endoconidiophora fagacearum Bretz, the cause of oak wilt. Unpublished Ph.D. Thesis. Ames, Iowa, Library, Iowa State University of Science and Technology.

Fergus, C. L. and D. C. Wharton. 1957a. Oak wilt. Histological studies of host reaction and pathogen. $\mathrm{Pa}$. Agr. Expt. Sta. Prog. Rpt. No. 168.

and

1957b. Production of pectinase and growth-promoting substance by Ceratocystis fagacearum. Phytopathology 47:635-636.

Gerry, Eloise. 1914. Tyloses: their occurrence and practical significance in some American woods. J. Agr. Res. I: $445-469$.

Gilbert, S. G. 1940. Evolutionary significance of ring porosity in woody angiosperms. Bot. Gaz. 102:105-120.

Henry, B. W., C. S. Moses, C. A. Richards and A. J. Riker. 1944. Oak wilt: its significance, symptoms and cause. Phytopathology 34:636-647.

and A. J. Riker. 1947. Wound infection of oak trees with Chalara quercina and its distribution within the host. Phytopathology 37:735-743.

Hepting, G. H., E. R. Toole and J. S. Boyce, Jr. 1951. Perithecia produced in an unpaired isolate of Chalara quercina and its possible significance in oak wilt control. Plant Dis. Rptr. 35:555.

Hoffman, P. F., Jr. 1951. Physiology of Chalara quercina H. and chemicals for control of oak wilt. Unpublished Ph.D. Thesis. Ames, Iowa, Iibrary, Iowa State University of Science and Technology.

Jewell, F. F. 1956. Insect transmission of oak wilt. Phytopathology $46: 244-257$.

Jones, T. W. 1958. Mortality in wilt infected oaks. Plant Dis. Rptr. 42 : $552-553$.

and A. D. Partridge. 1961. The importance of root grafts in oak wilt spread in Missouri. Plant Dis. Rptr. 45: 506-507.

Klein, G. 1923. Zur Atiologie der Thyllen. ztschr. f. Bot. $15=417-439$. 
Kozlowski, T. T., C. H. Beckman and J. E. Kuntz. 1961. Diameter growth characteristics of oak trees. Univ. Wisc. For. Res. Note No. 70.

Kuntz, J. E., C. H. Beckman and A. J. Riker. 1952. The development of oak wilt symptoms in relation to date and place of infection and concentration of fungus spore load. Univ. Wisc. For. Res. Note No. 4.

and A. J. Riker. 1950. Root grafts as a possible means for local transmission of oak wilt. (Abstract) Phytopathology $40: 16-17$.

Leach, J. G., R. P. True and C. K. Dorsey: 1952. A mechanism for the liberation of spores from beneath the bark and for diploidization in Chalara quercina. Phytopathology 42: $537-539$.

Marchetti, M. A. 1959. Colonization of red oaks by Ceratocystis fagacearum (Bretz) Hunt. Unpublished M. S. Thesis. Ames, Iowa, Library, Iowa State University of Science and Technology.

- 1960. Recovery of white and gray isolates of Ceratocystis fagacearum from red oaks. Iowa Acad. Sci. Proc. 67:109-113.

Norris, D. M., Jr. 1953. Insect transmission of oak wilt in Iowa. Plant Dis. Rptr. 37:417-418.

Parmeter, J. R. and J. E. Kuntz. 1954. Oak wilt development in bur oaks. (Abstract) Phytopathology 44 $4: 502$.

and A. J. Riker. 1956. Oak wilt development in bur oaks. Phytopathology $46: 423-426$.

Preston, J.F. and F. J. Phillip. 1911. Seasonal variation in the food reserve of trees. Forestry Quarterly 9:232-243.

Rumbold, Caroline. 1920. Causes for the production of pathological xylem in the injected trunks of chestnut trees. Phytopathology 10:23-33.

Sass, John E. 1951. Botanical microtechnique. 2nd ed. Ames, Iowa, Iowa State College Press.

Schoeneweiss, D. F. 1959. Xylem formation as a factor in oak wilt resistance. Phytopathology $49=335-337$. 
Scott, F. M. 1948. Internal suberization of plant tissues. Science 108:654-655.

Sinnott, E. W. 1918. Factors determining the character and distribution of food reserve in woody plants. Bot. Gaz. 66: 162-165.

Staley, J. M. and R. P. True. 1952. The formation of perithecia of Chalara quercina in nature in West virginia. Phytopathology 42:691-693.

Struckmeyer, B. Esther, C. H. Beckman, J. E. Kuntz and A. J. Riker. 1954. Plugging of vessels by tyloses and gums in wilt-infected oaks. Phytopathology 44:148-153.

and J. E. Kuntz. 1954. Histology of fungus mat development in wilting oak trees. (Abstract) Phytopathology 44:507.

and A. J. Riker. 1958. Histology of certain oaks infected with the oak wilt fungus. Phytopathology 48:556-561.

True, R. P., H. I. Barnett, C. K. Dorsey and J. G. Leach. 1960. Oak wilt in West Virginia. W. Va. Agr. Expt. Sta. Bull. 448T.

Wilson, C. L. 1961. Study of the growth of Ceratocystis fagacearum in oak wood with the use of autoradiograms. Phytopathology 51:210-215.

Wood, F. A. and J. E. Peterson. 1959. Fungi isolated from oak-wilted-infected and apparently healthy oak trees. (Abstract) Phytopathology 49:555.

Yelenosky, G. and C. L. Fergus. 1959. Absorption and translocation of solutions by healthy and wilt-diseased red oaks. Pa. Agr. Expt. Sta. Bull. No. 657.

Young, R. A. 1949. Studies on oak wilt caused by Chalara quercina. Phytopathology 39:425-441.

Yount, W. L. 1954. Identification of oak wilt isolates as related to kind of inoculum and pattern of disease spread. Plant Dis. Rptr. 38:293-296.

zuckerman, B. M. 1954. Relation of type and age of wound to. infection by Endoconidiophora fagacearum Bretz. Plant Dis. Rptr. 38:290-292. 


\section{ACKNOWLEDGEMENTS}

The author wishes to express his sincere appreciation to Dr. Harold S. McNabb, Jr. for his encouragement and guidance throughout this study and invaluable assistance in the preparation of this manuscript.

Acknowledgements are given to $\mathrm{Dr}$. Johin E. Sass for his timely counsel during the preparation and interpretation of histological material, and to Drs. Wendell $\mathrm{H}$. Bragonier and Lois Tiffany for their helpful criticism and suggestions during the preparation of the manuscript.

The author wishes to thank Miss Barbara Buchwald, Miss Winifred Bensend and John Clark for technical assistance, and to Messrs. Larry Weir, Arden Irvine, John Hart, David Conover and Virgil Howe for companionship and encouragement as fellow forest pathology researchers.

The research reported herein was supported by the Regional Research Project NC-22 of the United States Department of Agriculture. 